See discussions, stats, and author profiles for this publication at: https://www.researchgate.net/publication/348505134

\title{
Communication systems of high-speed railway: A survey
}

Article in Transactions on Emerging Telecommunications Technologies · January 2021

DOI: 10.1002/ett.4189

CITATIONS

0

5 authors, including:

Waled Gheth

Manchester Metropolitan University

15 PUBLICATIONS 42 CITATIONS

SEE PROFILE

Bamidele Adebisi

Manchester Metropolitan University

147 PUBlications 1,413 CITATIONS

SEE PROFILE

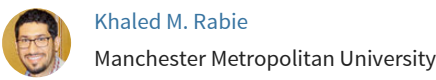

153 PUBLICATIONS 1,303 CITATIONS

SEE PROFILE

Georgina Diane Harris

University of Salford

57 PUBLICATIONS 433 CITATIONS

SEE PROFILE

Some of the authors of this publication are also working on these related projects:

CSNDSP 2018: Special Session on Green Communications and Networks View project

Project Wire integrity testing using intermodulation product processing View project 
DOI: $\mathrm{xxx} / \mathrm{xxxx}$

\title{
ARTICLE TYPE
}

\section{COMMUNICATION SYSTEMS OF HIGH-SPEED RAILWAY:}

\section{A Survey}

\author{
Waled Gheth*1 | Khaled M. Rabie ${ }^{1}$ | Bamidele Adebisi ${ }^{1}$ | Muhammad Ijaz ${ }^{1}$ | Georgina Harris ${ }^{2}$
}

${ }^{1}$ Department of Engineering, Manchester Metropolitan University, UK

${ }^{2}$ School of Science, Engineering and Environment, University of Salford, UK

Correspondence

*Waled Gheth, w.gheth@mmu.ac.uk

\section{Present Address}

John Dalton Building, Manchester

Metropolitan University, Chester St,

Manchester M1 5GD

\begin{abstract}
Summary
Modern railway services are required to deliver good quality services to the passenger throughout the whole journey. These include improved performances, safety, and reduce delays. There is also the requirement for in-train customer experience such as infotainment and access to reliable communication systems. The railway industry has employed different types and generations of communication systems in recent times. Signaling systems were used at the early stage of the railway services. Today, communication systems such as the second-generation communication system, also known as the global system for mobile communications (GSM), the Third-generation (3G) and the Fourth-generation (4G) are utilized in the railway industry. In this paper, we present a brief history of railway communication systems, their features and applications. In addition, we discuss the technical challenges and potential solutions of in-train communication systems and how data can be distributed on-board and between the train coaches using state of the art and hybrid communication technologies.
\end{abstract}

\section{KEYWORDS:}

High-speed railway, long-term of evaluation, optical wireless communications, power-line communications, visible-light communications.

\section{1 | INTRODUCTION}

High-speed railways (HSRs) offer transport that runs considerably fast in excess of $160 \mathrm{mph}$ for the new lines and in excess to 120 $\mathrm{mph}$ for the existing ones. Hence, HSRs can significantly improve the quality of service which in return leads to greater customer satisfaction ${ }^{1}$. However, the rapid development of the HSRs brings significant challenges in terms of industry, technology, and investment. For safety reasons and to handle the rapidly increasing traffic, a reliable communication system is required for HSRs. The current HSR communication systems have a foreseeable end to their lifetime and the need of a reliable communications system has become essential. Therefore, the assessment of the future of HSR mobile communication has recently started.

Different parameters are considered for the selection of a suitable system that can fulfill the requirements of HSR operations such as performance, service attributes, frequency band and industrial support. Fourth-generation (4G) broadband systems are one of the proposed systems to replace the current HSR communications systems. These systems, compared with Secondgeneration (2G) and Third-generation (3G) systems, have more capabilities as they offer higher data rates ${ }^{2}$. Currently, Fifthgeneration (5G) systems are still being discussed and will not be available before 2020. Therefore, they are not an option for the HSRs time frame ${ }^{2 \sqrt{33}}$. For their performance and high level of maturity, the $4 \mathrm{G}$ long-term of evaluation (LTE), LTE-railway (LTE-R) is more likely to be the most suitable and reliable technology for the next generation of HSR communication systems ${ }^{4 / 5}$. 
The non-negligible time that people spend commuting on trains can be used for reading electronic book, watching live programs, listening to music and playing video games. Some services, for instant ticketing and seat reservations, operate smartcatering and smart-retail services as well as supporting continuous condition monitoring of in-service rolling stock can be easily provided by using proper communication systems within the train. However, communications within the train is another issue as the electromagnetic waves can be severely attenuated by the metallic coating of the train ${ }^{6}$. Connecting the train to a network then distributing signals within and between coaches by using a proper distribution system could be a preferable scenario for communications inside the train ${ }^{6}$.

In order to achieve broadband services, different reliable communication system that can provide better performance and mobility to the end users can be adapted inside train coaches, such as wireless local area network (W-LAN), power line communication (PLC), optical wireless communication (OWC) services of the visible light communication (VLC), and a communication system which is based on a combination of PLC and VLC. W-LAN, most of the modern communication apparatus can use this system as they have W-LAN interface ${ }^{7}$. Besides W-LAN, femtocells or repeaters of the mobile communication standards themselves can be installed inside the coaches ${ }^{7}$, PLC is another candidate for in train communication. This can be used to achieve broadband services among the interconnected locomotive coaches. The principle of PLC is based on the use of the existing power lines in buildings, utility grid or vehicles to carry data and electricity, simultaneously ${ }^{8}$. This technology has been around for some decades, but it has only been used for limited applications such as, home automation, public lighting and narrow-band tel-remote relay applications. Recently, some studies showed promising results about using the PLC technology on board vehicles (automotive and aircraft). However, PLC might sooner play an important role in communication within the train, but it is still a new field of study 9 . To the best of our knowledge, very limited studies were carried out so far concerning broad-band PLC (BB-PLC) inside trains, particularly on PLC channel characterization $910 \mid 11$.

Mobile phone and laptop users can also enjoy broadband services using VLC which has recently matured. This technology can provide a significant range of benefits to the railway industry not only within the trains but inside stations as well; since every source of light on a train or inside a station could be used as a wireless hot-spot ${ }^{12 \mid 13}$. However, some light sources have advantages that made the VLC technology began to be used in various indoors and outdoors applications. Light Emitting Diode (LED) is one of the light sources of the VLC technology which can offer energy efficiency, long life expectancy and low maintenance cost ${ }^{14}$. Nevertheless, there are a number of challenges to be overcome and studied before this technology can be fully employed ${ }^{12}$.

The paper presents a brief history of railway signaling and the need for a reliable railway communication system that can meet the demand for rail transport. This is followed by an overview of HSR-dedicated communication systems. A comprehensive review of the current GSM-R system is introduced in this paper along with its essential challenges. LTE-R that has the ability to fulfill railway requirements and a likely candidate for next-generation HSR communications is also presented in this paper. The systems parameters and services of both GSM-R and LTE-R are described, and some limitations are discussed. Furthermore, comparisons between public networks and railway networks are made. The authors also present some reliable communication systems that can play a crucial role in the future of railway communication. Moreover, a survey on the communication systems that can be used to distribute signals inside and between train coaches is provided. The paper discusses the advantages and the challenging issues of such in-train communication systems.

The rest of this paper is organized as follows. A brief of history of railway communication is given in Section 2. Section 3 discusses the communication-based train control systems and the description and limitations of the GSM-R and the LTE-R systems. Section 4 presents communication within the train. Section 5 is the future work. Finally, the main conclusions are summarized in Section 6.

\section{2 | BRIEF HISTORY ON THE RAILWAY SIGNALING}

The survey of signaling and its development starts from the first purpose-built passenger-carrying railway with haulage by locomotives Liverpool and Manchester Railway which was opened in September 1830 1 . At this time the railway was entirely controlled by human signals. This is to ensure that the separation distance between trains is more than the required stopping distance. The concept of 'stopping distance' term is common among people. The highway code shows that about 20 meters is the required distance for a car with $30 \mathrm{mph}$ speed to be completely stopped and it requires three times of this distance if the speed is double ${ }^{1}$. The required stop distance for the modern trains even with superior brakes is as high as 1.25 miles as their speed is $200 \mathrm{~km} / \mathrm{h}$. To avoid colliding with obstructions and other trains there was a need of disciplines that can ensure a safe 
separation of moving trains. In 1830, none of the facilities which are considered today to be essential to operate the trains safely, for instance, telegraphs, telephones, line-side signals, etc, were available ${ }^{1}$.

At that time, the signaling systems were totally human-based. The guide-ways were divided into different sections, each section is about two miles, where a stationed railway policemen give hand signals to train drivers at each section. The policemen either give a clear signal to the coming train if there is no train in the section or indicate stop signal if the section is busy. There was one insurmountable disadvantage with this signaling system. If a train fault occurred and it stopped in a position, out of sight between two policemen, the guard of the train had to go back to indicate stop signal to the next train approaching the section.

In the late 1830s, the policemen hand signals were replaced by fixed-line signals. This system has the advantage of being visible to the train drivers from greater distances, where Red indicates 'Stop', Green 'Caution' and White 'Clear' in according to the convention ${ }^{1}$. A reliable form of communication was needed between the policemen in each section. Cooke and Wheatstone electric telegraph was the device that would present the required communication between the train policemen. In 1838, policemen used a telegraphic code to send words letter by letter where the telegraph's needle was moved to the right or left to allow messages to be sent and that is how policemen could report the entering and the leaving of the train to/from the section ${ }^{1}$.

The electric token system of single-line was used in the1890s instead of using telegraphic orders ${ }^{1}$. Track circuit, used as a practical mean to detect the presence of a train at a certain location. The use of this information would help to protect the train against other trains which are moving towards it. One of its benefits was the ability to control the signals (either power-worked semaphores or color-lights) without human interference. In the last three decades, electronics spread widely into all walks of life ${ }^{1}$. Adoption of processor-based interlocking systems was the most significant advance in those decades.

Recently, the demand of rail transport has increased due to many reasons including the growth of population, environmental requirements, urbanization increasing, and trains are more energy-efficient safer; and higher speed than the other land transport. Some studies ${ }^{15 \mid 16 / 17}$, showed that the rail mark in Europe grew by approximately 28 billion Euro in only five years with an expectation to grow more in the nearest future. This growth needs more modern communication-based signaling system to be

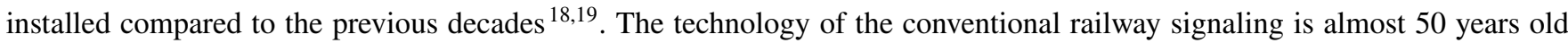
and it is regarded as the main reason of delays of the trains experienced every day. This explains why these systems are being replaced by new ones $20|21| 22$.

Today, a number of radio-communication-based signaling systems are installed worldwide for mass-transit operations. The use of radio communication makes such systems the first choice of some operators as they offer high resolution and real-time train control information, which consequently would minimize the number of equipment in the track-side and increase the capacity by reducing the distance between the trains in the line 232425 . Communications-based train control (CBTC) systems are regarded distinct from the European rail traffic management system (ERTMS), as they are specifically used for mass-transit which implies IEEE 802.11 wireless local area network (W-LAN) computer and radio communication for certain frequency bands.

\section{3 | COMMUNICATIONS-BASED TRAIN CONTROL (CBTC) OPERATION}

CBTC uses high capacity radio communication for train control information exchanging between the train and the wayside. This would enable both train control functions, automatic train operation (ATO) and automatic train supervision (ATS), and automatic train protection (ATP) subsystems. Simply, the state of the train including speed, direction, and location of the train is sent continuously over the radio connection to the wayside. The traffic control center at the wayside as a part of this system receives the information sent by the trains on the track then calculates two factors: maximum speed and distance that the train is allowed to proceed. The traffic control center also performs many other functions, such as trains scheduling and trains arrival time to destination ${ }^{26}$. CBTC system contains multiple Wi-Fi APs to ensure a continuous connection. These APs are placed at the track-side in a way that their coverage areas are overlapped. Each AP is then connected to the traffic control center by cable and communicates to the train through a radio connection. However, the installation cost of the cables which connect the APs to the wayside is very high and considered as one of the challenges of this system as it reaches to about 30,000 EUR/Km. The second challenge is the handover process, train ought to be connected to an AP all the time and as it moves should find a new suitable AP. Scanning, authentication, and re-association are the stages of the handover process in according to IEEE 802.1126.

Both scanning and authentication contribute the most to the latency of the process. The study in ${ }^{[27}$ showed that the latency of the scanning stage, the process of finding a suitable AP, is almost ninety percent of the total latency of the handover process. Generally, for latency reducing, active scanning is adapted in CBTC systems in a way that the announcement of searching for APs is proactively made by a node rather than waiting for APs announcement. The study in ${ }^{28}$ showed that data lost due to radio 


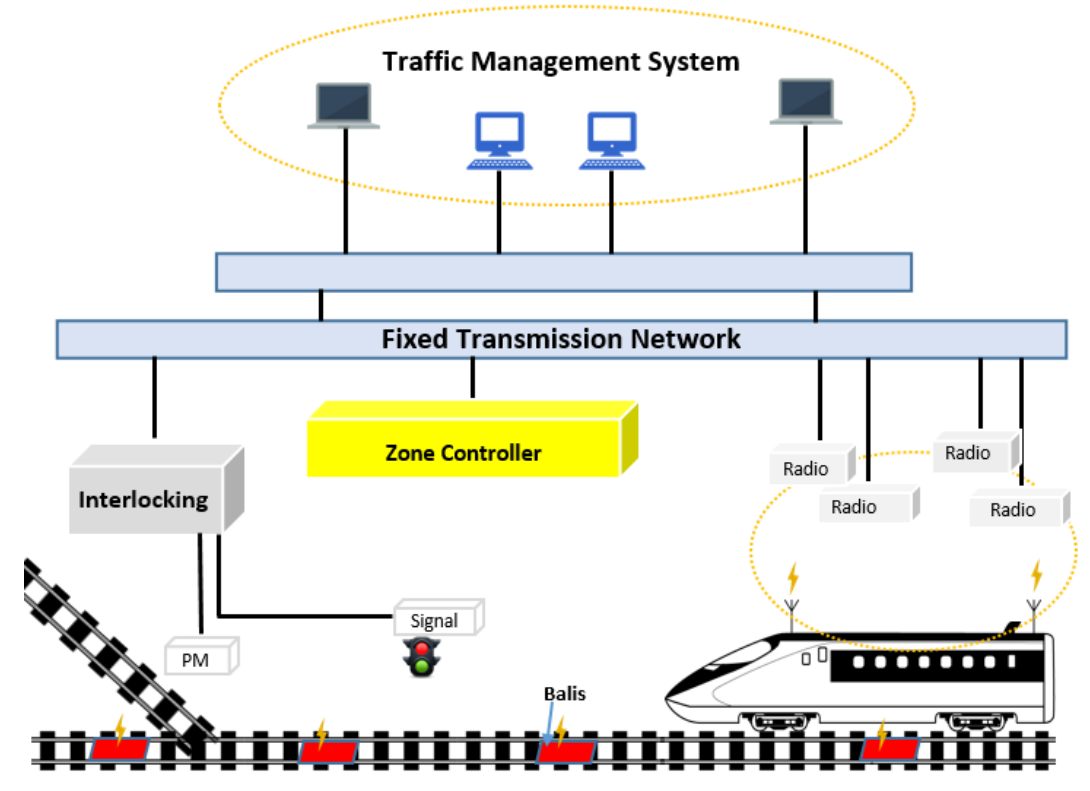

Fig. 1 CBTC system overview.

propagation effects is much less than that caused by the handover as the typical handover time is from 70-120 milliseconds in CBTC. However, two radios or more are installed at each end of the train to ensure a smooth transition, while one of these stays connected to the previous AP the other one switches to another AP.

A combination of devices is used in CBTC to determine the train speed and location such as transponders ("balises"), tachometers, Doppler radar, speedometers, odometers, and geolocation systems such as global positioning system (GPS) ${ }^{29}$. Based on the information collected by such devices, the wayside traffic controller measures the limit of movement authority (LMA), the maximum speed and distance that the train is permitted to travel and passes it back to the on-board equipment. Based on the information received back from the wayside ATC, the train speed and safety distance are continuously adjusted by the on-board equipment of the automatic train control. As a train passes over transponders which are mounted between rails, the transponders transmit the location information to the train through an antenna fixed under the train. Any inaccuracies in the location that could accumulate when the train travels over a distance will be corrected as soon as the train passes the next transponder 29 . Fig. 1 presents an overview of the CBTC system.

Real-time information exchange, provided by CBTC systems, explains why these systems would replace the conventional systems. Using this system reduces the headway distance between trains thus the capacity of the line increases and decreasing the number of the track-side equipment required by the previous system, for instance, color light signals and track circuits ${ }^{19}$. However, the main problem of using GPS is detecting the accurate location when two trains moving very close to each other on the railway. Also, the CBTC suppliers do not rely on the satellite signals inside tunnels. Moreover, the GPS is controlled by an external authority which makes the suppliers of CBTC hesitant about relying on such a system, thus its utilization in CBTC is supplementary.

As we previously mentioned, the rail tracks in conventional railway are divided into sections. The main purpose behind these sections is to make sure that separation distance between two neighboring trains is enough to stop the train in case of failure. These sections are called blocks and they are protected by a signal, track circuits are installed to determine the movement of the train inside the blocks. The length of any section is dictated by some factors, including the maximum speed of the trains, trains braking capabilities, the busyness of the line and the maximum allowed speed on the same line, etc. If a train is determined inside a block, no other trains are permitted to enter into this block and the entire block is considered as occupied. These blocks are called fixed blocks as their boundaries are fixed, regardless the speed of the train and its braking capability 2930 . The simplest way to describe this is that fixed block signaling creates an artificial separation between trains.

Even though the signaling community has been served well by this method for more than a century, the urban growth required a new reliable system to replace it. On the contrary, CBTC uses moving block operation, thanks to the real-time communication which is used to communicate between the train and the wayside. As the location of the train is continuously corrected and 


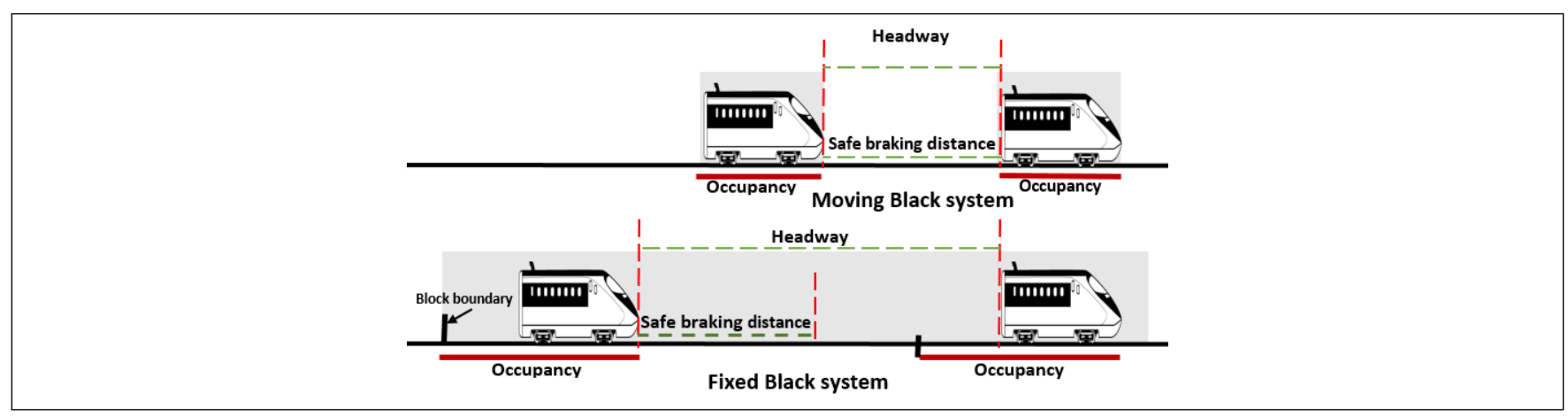

Fig. 2 The difference between fixed and moving blocks.

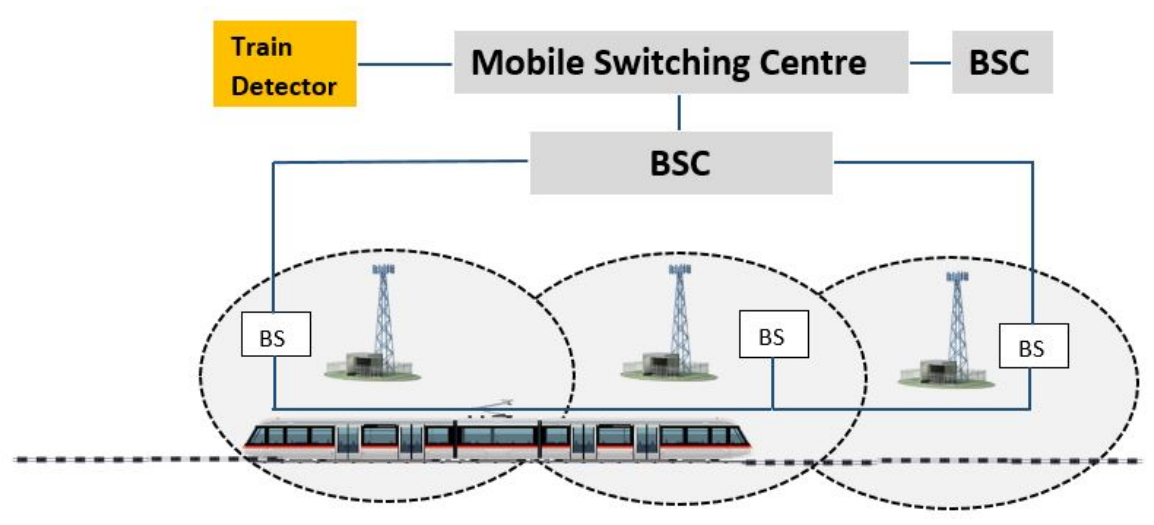

Fig. 3 GSM-R system architecture.

updated, the occupancy block moves with train with no fixed boundaries which allow trains to move closer to each other. The most important benefit of this paradigm is the safe braking distance was not anymore fixed but changeable depending on the speed of the train; if the train is moving at low speed the headway is short and expands as the train speed increases. As seen in Fig. 2. which shows fixed and moving blocks, the headway, the distance between two trains following each other, in the conventional signaling systems is relatively large compared to that in the CBTC systems. This means information, such as location and train speed, might not be received by the following trains within sufficient time. In such scenarios, the emergency brakes should be applied and the manual drive mode ought to be implemented ${ }^{16}$.

\section{1 | GSM-R}

GSM-R is an international wireless communication which has been specifically introduced to European rail companies to replace the conventional railway communication system as well as to ensure that trains can safely travel to different countries without any communications issues 31 . The GSM-R mobile technology is radio network which provides the radio coverage for both commuters and train crew. It is used for voice calls, data transmission and traffic control. In this system, the communication for drivers and signalers is secure as the coverage of the rail network is thorough, including deep cuttings and tunnels ${ }^{32}$. GSM-R and GSM system are basically the same but GSM-R has railway specific functions based on European standards and specifications ${ }^{2}$.

Each driving cab is equipped with a cab radio to be used by the crew of the train for communication purposes. Dedicated base stations (BSs) are installed beside the railway track to configure the GSM-R system. The distance between any two neighboring base stations is different from country to an other depending on the local environment, for instance, it is from 3-to-5 km in China and 7-to- $15 \mathrm{~km}$ in Europe ${ }^{2}$. The cell range or the area covered by each BS is around $8 \mathrm{~km}$, and the frequency band used by GSM-R system is around 800/900 MHz. However, there are extra frequency bands used in GSM-R on a national basis known as extended GSM-R (E-GSM-R). These frequency bands are $873-876 \mathrm{MHz}$ and $918-921 \mathrm{MHz}$, the former is for up-link and the latter is for down-link ${ }^{2}$. 
The BSs are linked together in groups and controlled by base station controller (BSC). This BSC also provides the connection between the BSs and the mobile switching center (MSC). The MSC is one of the mobile switching subsystem (SSS). The MSC is the network core which is responsible of the connection between the users of the system and managing the mobility of the users. Furthermore, its gateway is in charge of connecting between the GSM-R network and other public networks ${ }^{33}$. The second function of the SSS is; the dynamic database and visitor location register (VLR). When the mobile station (MS) moves to a new control area, the home location register (HLR) provides the required data to the new VLR such as location registration, the VLR stores the information of the users which is initiated by the HLR ${ }^{33}$. In order to enable the GSM-R system to track the position of the train and provide services to that train, the journey details should be entered into the cab radio of the train by the driver.

The GSM-R system offers different services to its users. Point-to-point and group calls are some of the services which is provided by the system, where the former is a similar to the normal telephone call as it is between two users only, the latter is a group call and using the press to talk (PTT) is required to take part in this call conversation. Every user in the GSM-R area where the group call was aimed at will be connected to the conversation and will be leaving the call when they leave the aimed cell or area. Operational text messages is another service that the GSM-R provides. GSM-R users (drivers, signalers and controllers) can send different types of operational text messages which would improve the communications between them, such as contact signaler, wait, standing at signal and acknowledge. The GSM-R system architecture is shown in Fig. 3

Even though the GSM-R system is very relevant to the high speed trains and is based on a mature technology, but it has some considerable limitations. Handover is the most crucial issue that can affect the quality of service (QoS) in GSM-R systems ${ }^{34}$. Mobile-controlled handover, network-controlled handover and mobile-assisted handover are the three strategies of the communication systems. However, the latter where both up-link and down-link signals are involved, is the handover scheme applied in GSM-R ${ }^{[35}$. The GSM-R handover process is controlled by BSC, which initiates the handover whenever the signal strength report received from the MS shows that the signal strength of the target cell is by far stronger than the serving cell ${ }^{33}$. The small area covered by each BS and the high mobility of the trains make the handover process in GSM-R systems different and more difficult than that of the GSM systems. This also increases the number of handovers during one voice call or data transmission ${ }^{2}$.

The transmission of the signal in the GSM-R system suffers from shadowing and multi-path effect. In addition to this, transmission in GSM-R networks is affected by the Doppler shift due to the high speed of the MS 36 . The growth of both GSM-R and public networks has increased the electromagnetic (EM) interference between both networks 2 . The second source of conducted and radiated EM interference is caused by the arcing between the contact wire and pantograph during the current collection process ${ }^{37}$. This is a common phenomenon in electrified railway systems that predominantly occurs at higher speeds and loads. This interference might cause a significant impairment of communication as well as network loss along the rail tracks $\frac{38}{38}$. In order to avoid such interference, and ensure reliable transmission, this problem has been investigated by a number of research $\frac{39140 \mid 41}{\text {. }}$ A number of solutions are proposed in the literature to eliminate the effect of the EM interference on the performance of the GSM-R systems, such as increasing the coverage level, processing the signal at the receiver and enhancing the receiver part on the trains ${ }^{42}$.

The dedicated frequency bandwidth and circuit-switched based design of the GSM-R limit its capacity. Only 19 frequency channels are available in the allocated $4 \mathrm{MHz}$ bandwidth to the GSM-R systems which leads to some technical issues in providing services to all trains in busy areas at the same time ${ }^{43}$. In different scenarios such as a high volume of traffic the circuit-switched can not ensure a reliable voice and data transmission at the same time and the need to an alternative approach becomes essential ${ }^{44}$. In such cases, the packet-switched, based on general packet radio service (GPRS) and and enhanced GPRS (EGPRS) services, can be used to increase the capacity of the GSM-R systems by improving the use of the frequency spectrum ${ }^{44}$. Capability is considered as another challenge of the GSM-R system. The insufficient transmission rate and the system delay can hardly support any real-time applications and emergency communication ${ }^{43}$. The gaussian minimum-shift keying (GMSK) modulation scheme used in GSM-R is much less flexible in terms of allocating resources to the users than the orthogonal frequency-division multiple access (OFDMA) used in LTE-R ${ }^{45}$.

Even though the GSM-R continuity is ensured for the next few years, but due to the mentioned limitations, the need of switching to another system which can overcome these limitations is necessary. At the current time LTE-R based on LTE standards might be the preferable candidate to replace the GSM-R system ${ }^{44}$. The deployment of LTE-R systems can improve the performance of the HSR communication systems in terms of capacity and capabilities as it uses a fully packet-switchedbased network ${ }^{\sqrt{43}}$. Furthermore, the advanced multiplexing and modulation used by LTE-R can improve the spectral efficiency. Moreover, LTE is also a well established and off-the-shelf system and the coexistence between the previous HRS communication and the LTE-R is predicted to last for some time which is strongly support the move from GSM-R to LTE-R ${ }^{2}$. 


\section{2 | LTE-R}

Due to the required reliability and availability of the railway communication system, public networks have been developing for many years from systems with limited capability such as GSM to systems that can provide better performance in terms of data rates such as $\mathrm{LTE}^{2246}$. The main aim of these systems was to improve the speed and capacity of wireless networks. For this goal new digital signal processing and modulations techniques were employed at the beginning of the last decade. A further aim was making the system architecture less complicated by redesigning to an IP-based network which can ensure less transfer latency than the previous wireless systems ${ }^{43}$. Thanks to these reasons, that the LTE-R, which is based on LTE standards, is considered as the best candidate that can replace the current railway communication system at the current time ${ }^{2}$. In this regard, some preliminary recommendations were issued by the international union of railways (UIC) on the feasibility of using standard LTE as the replacement of the current railway communication system ${ }^{43}$. However, the first LTE-R network is already scheduled to take place in some countries by the beginning of next decade ${ }^{2}$. Fig 4 shows the development history of wireless communication systems from the GSM to 4G. Compared to the GSM-R system, LTE-R system offers a high data rate up to 50 and 10 Mbps

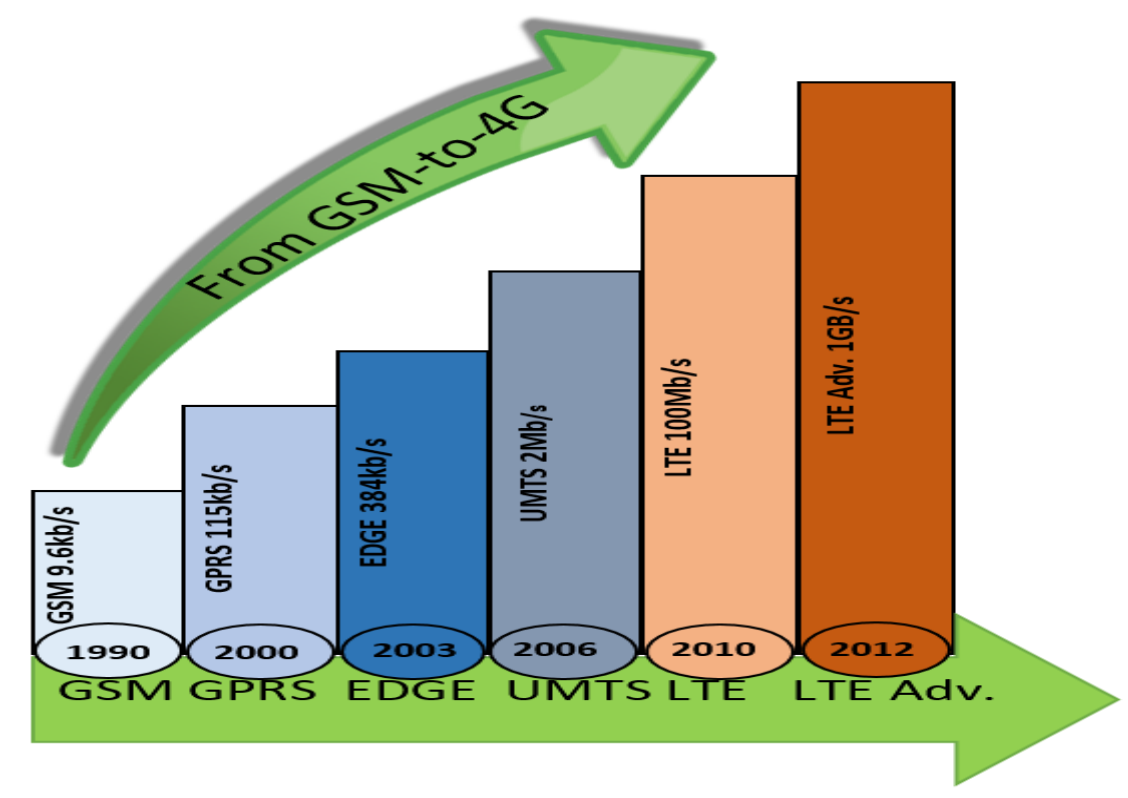

Fig. 4 The development of wireless communication systems from the GSM to 4G.

for down-link and up-link, respectively. QPSK/16-QAM is the modulation scheme used in the LTE-R system, whereas GSM-R uses GMSK modulation scheme. The handover process in GSM-R system is a hard change, that is, the connection of the MS is entirely broken with the current BS before it is being switched to the target BS. This handover technique is also known as break-before-make. Although this process appears seamless to the network users, there is a possibility that a short break in the connection can be easily noticed particularly during high speed movement of the train that causes a frequent handover during one call. Unlike the hard handover that is implemented in GSM-R system, the LTE-R system uses the soft handover between the $\mathrm{BSs}^{47}$. Here, the MS is always connected to at least one channel. This process is known as make-before-break as the MS keeps the connection for the previous BS until it gets connected to the target BS. In the downlink direction of the soft handover scenario, when the MS is in the overlapping area coverage of neighbouring BSs, the signals that are received from these BSs are combined at the receiver. However, in the uplink direction, the signals from the BSs are compared frame-by-frame basis, and the best one is selected. Although the make-before-break process is more complex compared to the hard handover process, but it can drastically improve the QoS by reducing the probability of call drop and eliminating the interference ${ }^{47}$. Table 1 shows some characteristics of hard and soft handover processes.

However, this is considered one of the major challenges of the LTE-R system. The system is meant to support high-speed trains up to $500 \mathrm{~km} / \mathrm{h}$. The high speed of trains and the small area covered by each BS lead to increasing the number of handovers between the cells in LTE-R network ${ }^{35}$. To start the handover process in LTE-R system, the user equipment reports the signal 
TABLE 1 Characteristics of hard and soft handover processes.

\begin{tabular}{|c|c|c|}
\hline Characteristic & Hard & Soft \\
\hline Complexity & Less & High \\
\hline Disruption time & High & Less \\
\hline Network resources & Uses less & Uses More \\
\hline Extra radio link & Not required & $\begin{array}{c}\text { MS consumes extra radio } \\
\text { link }\end{array}$ \\
\hline Additional hardware & Not required & $\begin{array}{c}\text { More hardware is } \\
\text { required-12 km }\end{array}$ \\
\hline Packet loss & High & Less \\
\hline
\end{tabular}
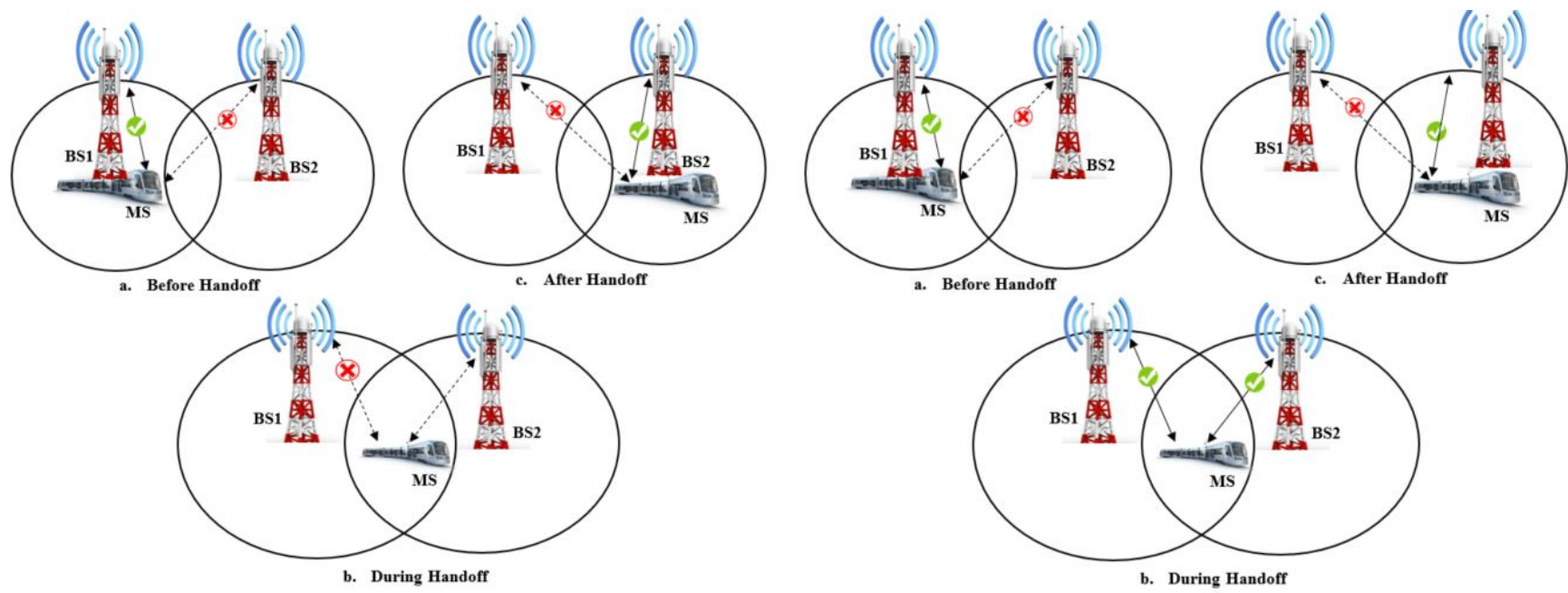

Fig. 5 Mechanism of Hard Handover.

Fig. 6 Mechanism of Soft Handover.

strength to the serving cell which then decides whether the MS needs to be connected to the target cell or not. If the handover is needed, the current cell sends a handover request message to the target cell then the target one sends acknowledge message if it accepts the handover request. A path switch request or handover notify message is then sent by the target cell to mobility management entity which in turn informs the serving gateway about the change in the path of the MS ${ }^{47}$. Figs 5 and 6 show the mechanisms of hard and soft handovers, respectively.

The perfect use of the frequency and spectrum of LTE-R is vital to consider in order to provide a reliable and efficient communication system for HRS. Currently, $1 \mathrm{GHz}$, such as $1.8,2.1,2.3$, and $2.6 \mathrm{GHz}$ are the bands where the most of LTE system work at ${ }^{2]}$. Although the availability of bandwidths is higher at high frequencies which gives more data rate, but longer distance coverage can be provided by lower frequency bands. Furthermore, it is known that the propagation loss and fading are considerably larger at higher frequency bands. Therefore, lower frequency bands $450-470 \mathrm{MHz}$ have been widely considered for $\mathrm{HRS}^{2}$. The use of this low- frequency band can allow countries reducing the cost of the network by reusing the existing GSM-R mast sites $^{2}$. Table 2 shows some parameters differences between GSM-R and LTE-R.

There are some differences between both public LTE and LTE-R networks, such as the layout of network, architecture, system parameters and QoS. The reliability has more consideration than capacity in LTE-R networks configuration ${ }^{2}$. Although the capacity is less considered than the reliability in LTE-R, the LTE-R cell can serve 27 trains simultaneously at one of the main train stations and the capacity provided by the cell is enough to serve more trains at the same time ${ }^{48}$. The LTE-R network is supposed to be able to operate at a very high speed up to $500 \mathrm{~km} / \mathrm{h}$, sometimes in very complex railway environments. A growing number of research works has been contacted to prove that the LTE-R can fulfill the railway requirements ${ }^{49 / 43[50 \mid 48}$. Simulation 
TABLE 2 GSM-R and LTE-R parameters.

\begin{tabular}{|c|c|c|}
\hline Parameters & GSM-R & LTE-R \\
\hline Up-link frequency & $870-880 \mathrm{MHz}$ & $\begin{array}{c}450 \mathrm{MHz}, 800 \mathrm{MHz}, 1.4 \\
\mathrm{GHz}\end{array}$ \\
\hline Down-link frequency & $921-925 \mathrm{MHz}$ & $1.8 \mathrm{GHz}$ \\
\hline Bandwidth & $0.2 \mathrm{MHz}$ & $1.4-20 \mathrm{MHz}$ \\
\hline Modulation & GMSK & QPSK/16-QAM \\
\hline Cell range & $8 \mathrm{~km}$ & $4-12 \mathrm{~km}$ \\
\hline Maximum mobility & $500 \mathrm{~km} / \mathrm{h}$ & $500 \mathrm{~km} / \mathrm{h}$ \\
\hline MIMO & No & Only 2x2 \\
\hline Data transmission & Requires voice call & Packet switching (UDP \\
& connection & data) \\
\hline Handover procedure & Hard & $50 / 10 \mathrm{Mbps}$ \\
\hline Data rate, downlink/uplink & $172 \mathrm{Kbps}$ & $2.55 \mathrm{bps} / \mathrm{Hz}$ \\
\hline Peak spectral efficiency & $0.33 \mathrm{bps} / \mathrm{Hz}$ & \\
\hline
\end{tabular}

results and technical analysis of these studies have proven that the LTE-R system is the preferred candidate for the future of the railway communication system 48 .

LTE-R can provide different services that can significantly improve railway services in terms of capacity and passengers. To improve the tracking accuracy, the train location is detected by on-board equipment, this information is then transmitted through wireless communication with a delay time less than $50 \mathrm{~ms}$ which is considered as a real-time transmission ${ }^{2}$. The system also offers a real-time train, weather conditions and railway infrastructure video monitoring with transmission latency less than 300ms. The LTE-R system provides railway emergency communications in case of any emergencies that can disturb the railway users, such as natural disasters and accidents. In such cases, an immediate voice, video, data communications can be established between the site of the accident and the control center ${ }^{2}$. There are some other services that the LTE-R system can provide to the train commuters, for instance, seat-reservation, electronic-ticketing, and interaction of passenger information ${ }^{2}$.

There are different issues associated with the employment of the LTE-R. The coexistence between the LTE public safety network and the LTE-R network is one of these issues. Basically, public safety network, such as police, firefighters and ambulance, and LTE-R networks use the same frequency bands which are 718-728 MHz and 773-783 for up-link and down-link, simultaneously ${ }^{51}$. Therefore, one of the major challenges is how to eliminate radio interference between both networks as both of them are more concerned about reliability and safety 51 . High mobility of trains leads to Doppler shift which is a shift of the received frequency and in some cases this might lead to a phase shift of the signal and can impair the reception of angle-modulated signals. However, tracking and compensation are possible for the Doppler shift as trains move with a well-known speed and the position and real-time are recorded ${ }^{2}$.

Propagation loss in the HSR environments, such as cuttings, tunnels, bridges, and train stations can considerably affect the performance of the LTE-R system ${ }^{[52}$. Although some measurements were carried out to characterize the channel for such environments, it is essential to develop a appropriate channel model which can perfectly represent the transmission channel in the HSR environments ${ }^{2}$. There are other challenges which should be taken in consideration for the designing of LTE-R system such as large Doppler spread which can cause signal-to-interference-plus-noise ratio degradation and OFDM corruption. Furthermore, delay spread which can lead to a loss of orthogonality between the OFDM sub-carriers and a special category of guard interval. Moreover, linear coverage with directional antennas is used in railway communication systems ${ }^{2}$. Although this type of coverage consumes less power and provides better performance, at some train locations the outage probability is high due to the shadow fading impact ${ }^{2}$. Due to these limitations and the requirement of high-capacity communications for passengers of the next generation of the railway, finding an alternative technology to the current railway communication systems has become necessary. However, the challenges of providing the required services and focusing on QoS, reliability and capacity should be the principal issues of the candidate technologies of the future of the railway communication. 


\section{3 | The Fifth-Generation (5G) Communications}

The maximum capacity of the current communication systems is still insufficient to handle the required data rate for the applications of the future generation of the railway. These applications include high-definition videos, images and important information in real time transmission for train-to-infrastructure, train-to-train and instructions-to-instructions. All of the existing technologies support data rates up to $100 \mathrm{Mbps}$ only. The main reason behind this is that these technologies work frequencies lower than $6 \mathrm{GHz}$. Therefore, to acquire sufficient bandwidth, the jump to a technology that uses higher bandwidth is essential. However, the interest of implementing a capable system to handle the critical and noncritical communications of the railway has increased $[53$. Both critical and noncritical communications have very specific requirements and any frequent failure of them can affect the service reliability. However, the extremely high frequency (EHF) bandwidth, which is well studied for 5G technology, can tackle the issue of the shortage of frequency band resources.

Although 5G technology is not in the final stage, its final form is expected to be determined by 2020 as the entire industry is working on this task. This technology with its high-data rate is expected to play a crucial role in applications that require more reliable and low-latency communication such as intelligent transportation systems. Technologies including millimeter waves, beam-forming, M-MIMO, small base stations, and full duplex play the essential role in the development of this 5G technology. The 5G networks will be built upon the existing wireless systems including the $2 \mathrm{G}, 3 \mathrm{G}$ and $4 \mathrm{G}$ and it aims to retrofit the architecture of the current communication systems (i.e., 4G) ${ }^{54}$. These networks can benefit from the current investment of the $4 \mathrm{G}$ networks by expanding their capabilities ensuring that $5 \mathrm{G}$ is interoperable with $4 \mathrm{G}$ and provides the desired performance for the railway communications.

Latency is one of the items that have been improved in $5 \mathrm{G}$ technology which can help enabling some functions that require a quick response such as auto-driving trains. The new technologies that are implemented by $5 \mathrm{G}$ aim to reduce the latency in such networks to $1 \mathrm{~ms}$ compared to $70 \mathrm{~ms}$ of data-transmission latency of the current $4 \mathrm{G}$ technology. Thanks to the millimeter waves technology used by the 5G that makes its spectrum bandwidth higher than the existing technologies thus enhances the speed of data transmission and offer better connectivity between the train and the wayside ${ }^{54}$. For example, the available bandwidth of the 5G networks is nine GHz, while only $100 \mathrm{MHz}$ of spectrum bandwidth is available in 4G-LTE networks. The targeted date rate of the fifth generation technology is $20 \mathrm{Gbps}$, which is achievable with its recommended bandwidth and the implementation of massive $\mathrm{MIMO}^{54}$. This makes the $5 \mathrm{G}$ technology more reliable to be used for railway communication than the current communication systems.

Even though the $5 \mathrm{G}$ technology seems to be the best candidate for the existing railway communication systems, there is a number of challenges to consider. First of all, self-interference cancellation. Looking at the fundamental nature of the fifth generation technology, self-interference can have a considerable effect on $5 \mathrm{G}$ networks ${ }^{55}$. Secondly, the power consumption of the overall system. As the fifth generation network utilize larger bandwidth compared to the current technologies which means more data rate thus this technology consumes more energy for data transmission ${ }^{56}$. Furthermore, in multi-Gbps communication networks, data transmission is restricted by the characteristics of data propagation. It was reported that a very-high path loss and attenuation are associated with high frequencies. This should be compensated by either increasing the transmit power or the gain of the receiving antenna ${ }^{56}$. Moreover, due to the nature of the wavelength of the millimeter waves and the railway environment, the transmission can be easily blocked or shadowed $[57$.

\section{4 | INSIDE TRAIN COMMUNICATION}

The time that people spend commuting on trains can be used for different interesting things, such as reading electronic books, watching live programs, listening to music and playing video games as long as their electronic devices are connected to the internet or communication systems. The required connection can be made into two different scenarios. The first scenario, every single electronic device can be connected to the communication network individually. In this scenario, the transmission to the mobile equipment is highly attenuated by the metallic coating of coaches particularly the modern ones. Furthermore, such communication suffers from the Doppler shift due to the high speed of the train and the high transmission frequency of the wireless networks ${ }^{6}$. In most of the cases, the second scenario is preferable. In this scenario, the train is connected to a public network then the signal is distributed inside the train coaches using a proper distribution system ${ }^{6}$.

Dedicated wireless networks, such as GSM-R and LTE-R, are used to provide trains with different communication services. These two networks are dedicated particularly to support the HSR by providing specific information that can help to monitor and control the traffic of the trains and thus to eliminate train accidents ${ }^{6}$. However, the public networks, such as GSM and LTE 
are designed with specific cells overlapping. This overlapping is large enough to make a full handover procedure between two neighboring cells in the HSR system. The main issue of the public networks that they do not provide a network coverage for the entire railway tracks. Particular areas in the railway track, such as remote areas and areas near to the tunnels and bridges usually suffer from holes in the public network coverage. This is because of the lack of customers besides such areas thus public operators do not install their equipment there. Recently, the HSR operators invited the public network operators to provide communication services in such places ${ }^{6}$.

The reliability of in-train communication systems in the second scenario depends on two parameters, receiving equipment and the distribution system inside the train. Generally, a roof-mounted antenna fixed on the train roof works well as a receiving equipment. Various communication systems can be used for signal distribution within the train coaches. W-LAN can be installed in each train coach to distribute signals to the passengers's user equipment (UE) ${ }^{58}$. Furthermore, the technology of VLC that recently has matured is predicted to play a crucial role in the railway industry 12 . Moreover, PLC systems have been used for different indoor applications and it can be used for distributing the signals inside the train using the pre-installed power lines ${ }^{9}$. The main issue with PLC systems is that mobile users do not have an access to the power lines. In such cases, cooperative PLC/wireless or PLC/VLC is an option. In this section, we discuss how signal can be distributed within the train.

\section{1 | Wireless Access Point}

As previously mentioned that the electromagnetic waves are significantly attenuated by the metallic shielding of the train coaches. For this reason, communication between UE on-board and the public networks outside the train can be improved by using a roof-mounted antenna to communicate with the public networks. Then a central distribution system can be installed inside train coaches to communicate between the UEs on-board and the roof-mounted antenna. Almost all of the modernized electronic devices have a W-LAN interference so they can use this system for communication purposes ${ }^{6}$. This system can offer different services, such as internet access and entertainment services to the commuters of the high speed trains with sufficient data rate ${ }^{59}$.

The W-LAN system can be installed either in each coach of the train or one system serving all coaches. However, if the former configuration is installed, then a receiving device (i.e a roof-mounted antenna) is needed to be located in each coach to communicate with the W-LAN on-board and the base stations of the public networks. On the other hand, only one receiving device is needed if the latter system configuration is installed. Then the connection between any two neighboring coaches should be wireless to ease the coaches assembly process at the stations. As mentioned above, a receiving device is located in each coach or only in one coach depending on which way the WLAN system is installed ${ }^{58}$. This device will be responsible for connecting the W-LAN in the train with the outside communication systems. The receiving device should support LTE modem type of functionality and a wire-line to be able to communicate with both outside and in the train systems, respectively 58 . Fig. 7 shows W-LAN system inside a train coach.

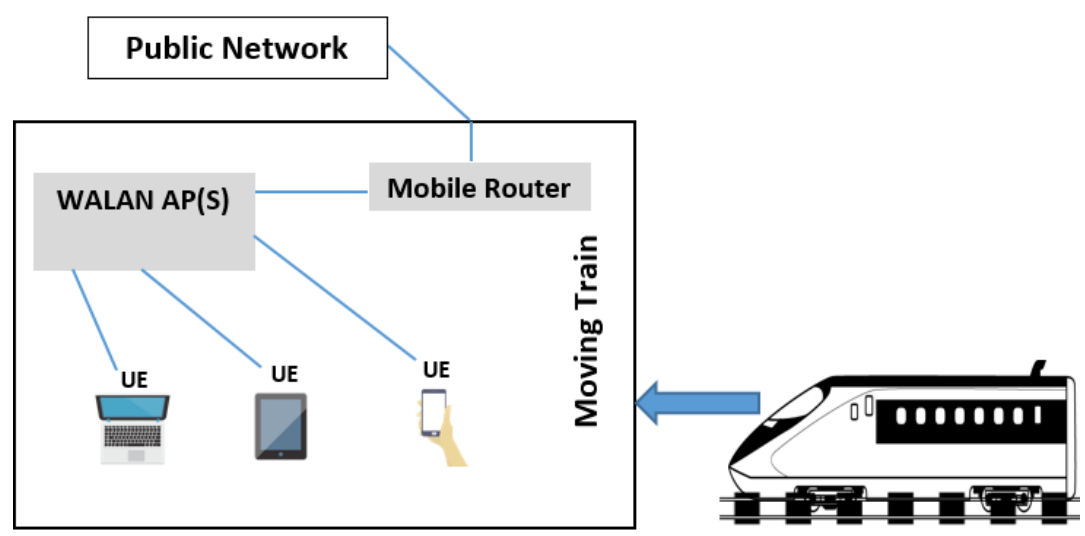

Fig. 7 W-LAN system inside a train coach.

Another installation design is to attach receiving devices to the roof of the first and the last coaches of the train. This installation offers to the commuters a high-capacity access to the public networks and reduces the fixed infrastructure requirements 6 . Furthermore, both of the receiving devices are able to distribute the signal inside all of the train wagons. Therefore, when one 
TABLE 3 Main standards of the Wi-Fi IEEE 802.11.

\begin{tabular}{|c|c|c|c|c|}
\hline Standard & IEEE 802.11A & IEEE 802.11B & IEEE 802.11G & IEEE 802.11N \\
\hline Approval date & July 1999 & July 199 & June 2003 & October 2009 \\
\hline Data rate & $54 \mathrm{Mbps}$ & $11 \mathrm{Mbps}$ & $54 \mathrm{Mbps}$ & $600 \mathrm{Mbps}$ \\
\hline $\begin{array}{c}\text { Modulation } \\
\text { schemes }\end{array}$ & OFDM & CCK or DSSS & $\begin{array}{c}\text { CCK, DSSS, or } \\
\text { OFDM }\end{array}$ & $\begin{array}{c}\text { CCK, DSSS, or } \\
\text { OFDM }\end{array}$ \\
\hline RF band & $5 \mathrm{GHz}$ & $2.4 \mathrm{GHz}$ & $2.4 \mathrm{GHz}$ & 2.4 or 5 GHz \\
\hline $\begin{array}{c}\text { Number of spatial } \\
\text { streams }\end{array}$ & 1 & 1 & 1 & $1,2,3$, or 4 \\
\hline Channel width & $20 \mathrm{MHz}$ & $20 \mathrm{MHz}$ & $20 \mathrm{MHz}$ & 20 or $40 \mathrm{MHz}$ \\
\hline
\end{tabular}

of the receiving devices is out of the public network coverage the other one is still communicating between the UE on-board and the public network. This is particularly in areas that suffer from small holes in the public network coverage, such as short tunnels and bridges ${ }^{60}$. For all of the above-mentioned installations, although the train is in high speed and passenger equipment are in high mobility state relative to the fixed base stations of the public networks, the user equipment is stationary relative to the in-coaches WLAN system ${ }^{6}$. However, different W-LAN types such as Wi-Fi and WiGig can be installed inside train coaches for signal distribution.

The Wi-Fi is a well-known cost effective W-LAN technology. Wi-Fi IEEE 802.11 is the main standard of the Wi-Fi. The different standards of this main one are shown in Table 3 The allowed achievable throughput is 450 Mbps on every available frequency bands ( 2.4 and $5 \mathrm{GHz}$ ) in IEEE $802.11 \mathrm{n}$. This is almost five times the previous IEEE 802.11 main standards ${ }^{61}$. Unlike the other main standards of IEEE 802.1, the IEEE 802.11n standard relies on multiple-input-multiple-output (MIMO) technology. Furthermore, The bandwidth, due to the aggregation of channels, is increased from $20 \mathrm{MHz}$ for the other main standards to $40 \mathrm{MHz}$ for IEEE $802.11 \mathrm{n}$ standard ${ }^{61}$. However, the recent Wi-Fi standard which was developed at the beginning of this decade and was approved in the last few years is Wi-Fi IEEE 802.11ac standard. A $500 \mathrm{Mbps}$ is the achievable theoretical throughput of this standard and a $7 \mathrm{Gbps}$ of throughput can be achieved by implementing the MIMO and multiplexing techniques ${ }^{62}$. Although the Wi-Fi technology has a larger transmission range than the Wi-Gi one, the latter provides better throughput.

Recently, the millimeter wave technology, wireless gigabit (Wi-Gi), has gained the researchers ' attraction due to the 6 Gbps of throughput that this technology offers to its users. This Wi-Gi is commonly known as IEEE 802.11ad $\mathrm{d}^{6364}$. Both bodies the wireless gigabit Alliance and IEEE 802.11ad have developed the industrial standard of the Wi-Gi which has been issued by IEEE in late 2012. The main aim of this technology is to be used to transfer a high-volume of data with a throughput of around 7 Gbps over a relatively short range. It operates at $60 \mathrm{GHz}$ frequency with $9 \mathrm{GHz}$ bandwidth from 57 to $66 \mathrm{GHz}$ which makes the $7 \mathrm{Gbps}$ of throughput is achievable ${ }^{63}$. In addition to the high-speed data rate offered by the $\mathrm{Wi}-\mathrm{Gi}$, it also provides a secure and protected transmission over a short distance with low latency 6 . Table 4 presents a summary of the salient features of 802.11ad.

The main issue of this technology is its very limited transmission range, as its typical transmission distance is $1-10 \mathrm{~m}$. Furthermore, due to its short wavelength at $60 \mathrm{GHz}$, the transmission is severely affected by the path loss, the loss can be as high as $28 \mathrm{~dB}^{62[64}$. However, this loss can be compensated by increasing the gain of the antenna. This leads to a narrower beam-width of the antenna, which is consequently will require antenna beam-forming. Omni-directional antennas are used by the previous IEEE 802.11 main standards, therefore this was not considered as an issue ${ }^{62}$. An extensive study was carried out by the authors of ${ }^{64}$ on planning and the formation of the Wi-Gi network. Two different network scenarios were investigated in order to extend the coverage of the Wi-Gi network. They concluded that the performance of the Wi-Gi network is affected by different parameters, such as network-load, the percentage of intra-LAN and internet devoted network traffic $\frac{64}{\text {. }}$

\section{2 | Visible Light Communication (VLC)}

One of the most significant current discussions in optical wireless communication technologies (OWC) is the light fidelity (LiFi) technology. This green technology is predicted to play an essential role in indoor communication applications. Instead of 
TABLE 4 Summary of the salient features of 802.11ad.

\begin{tabular}{|c|c|c|}
\hline Characteristic & Description & References \\
\hline Frequency & $60 \mathrm{GHz}$ ISM band & 6364 \\
\hline Throughput & $7 \mathrm{Gbps}$ & 63 \\
\hline Typical transmission range & $1-10 \mathrm{~m}$ & 62 \\
\hline Antenna technology & Beam-forming is used & 62 \\
\hline Modulation schemes & Single carrier and OFDM & 63 \\
\hline
\end{tabular}

using radio frequency, the short-range Li-Fi technology is based on the implementation of VLC. The light emits from the lowcost and energy-efficient LEDs is the transmission medium of this technology which makes its potential implementation in HSR due to low complexity and cost effective ${ }^{65166}$. The Li-Fi technology is better in terms of data exchanges security compared to the RF one, and it allows high data transmission rates up to $500 \mathrm{Mbps}$ over short distances. This is due to the nature of the nonbreached light waves and the line-of-sight $(\mathrm{LoS})$ of propagation of the LEDs lights ${ }^{66}$. Furthermore, this technology offers better performance than that provided by the RF technology. This is because of the non-electromagnetic interference, high transmission power and rich spectrum resources ${ }^{67}$.

Likewise, the other communication systems, the VLC contains three main components, namely transmitter, transmission medium, and receiver. In general, any light source can be utilized as a transmitter. However, LEDs are predicted to replace the other light sources in the future due to its energy consumption performance ${ }^{12}$. The LEDs such as white LEDs (WLEDs), which are one of the best light sources that can suit the VLC, are used for illumination and data transmission simultaneously 68 . This type of light sources has a higher expected lifespan compared to the other sources such as incandescent bulbs ${ }^{69}$. This shortrange technology uses the portion of the electromagnetic spectrum, which can be seen by the human eye, with wavelengths from $390 \mathrm{~nm}$-to- $750 \mathrm{~nm}$ as a transmission medium ${ }^{70}$. At the receiver, the photo-diode detector, the received signal is converted from light into an electrical signal which is then demodulated to the desirable information 12171 .

This fast growing technology can offer a wide range of services to the railway operations; such as entertainment, internet facilities (inside trains and underground stations), smart lighting inside train stations and improving railway safety ${ }^{12}$. In trains, LEDs can be equipped with transceivers to provide different multimedia facilities and internet services to train passengers ${ }^{12}$. Furthermore, using LEDs for providing internet services inside underground stations can help to tackle one of the major issues that face passengers in such areas. Moreover, due to the light sources distribution inside train stations, they can ensure a very seamless connectivity to the moving people and they can be used for in-station positioning and venue navigation ${ }^{12}$. On top of that, this technology can be used for ground-to-train communication and reducing the accidents 12 .

As an upcoming technology, a number of technical issues should be studied before this technology is fully implemented in the railway industry. First of all, the covered area by each LoS of the LED is relatively small. This is because of the rectilinear propagation of light which leads to frequent horizontal handover when the passenger is moving, thus instability of data reception ${ }^{65}$. During the handover process, the user changes the information with a central unit (CU) which can take up to 3000ms, this leads to a transmission loss ${ }^{72}$. Furthermore, light interference, this is due to the overlapping with the other neighboring light sources and sunlight 12 . However, different techniques are proposed in the literature for reduction of such interference . $^{73 / 74 / 75 / 76}$. For example, authors of ${ }^{[73}$ suggested choosing a suitable transmission band, which experiences relatively-less interference by other light-sources, to tackle the effect of this type of interference. The band can be chosen according to different factors, such as distance between the transmitter and receiver, irradiance angle, and incident angle. The results of this study have proven that the suggested technique works efficiently and can improve the performance of the VLC system by tackling the interference issue.

Both communication and illumination practices standards should be considered for the deployment of the VLC technology. This is different from any other communication system and adds the issue of coordination between different regulatory bodies 77 . Integrating the VLC as a new technology in an existing railway industry infrastructure can be a complex and costly task. The RF modulation schemes and the conventional modulation techniques which are used with optical communication cannot be 
used with VLC technology due to the flicker and dimming. The complexity of the transmitter and the receiver equalization is another issue in VLC system designing 77 . Another major challenge is to design an adequate transceiver which can be installed in small smartphones and laptops $\frac{12}{12}$. However, providing an up-link by the VLC link can be problematic. Therefore, as the Li-Fi technology does not interfere with the RF one, a cooperative VLC-RF system, where the VLC is used for a down-link and the RF is for up-link, can offer full connectivity and improves the QoS. Nevertheless, such cooperation leads to a vertical handover between the VLC and the RF systems which can cause more instability delay in data reception ${ }^{77}$.

\section{3 | Power-line Communication (PLC)}

In recent years, there has been an increasing interest in PLC technology. Simply, in this technology, the pre-installed infrastructure of wiring networks of a building or utility grid is utilized for both purposes caring electricity and data transmission to consumers. This advantage makes the PLCs a cost-effective and competitive technology for in home networking applications $\frac{78}{}$. According to its operating frequency this technology is grouped into two different groups, namely narrow-band PLC (NB-PLC) and BB-PLC. NB-PLC (low-frequency PLC) works at frequencies from 3-to-500 kHz and it is characterized by its low-data rate and long-range of transmission. 79180181 . For The BB-PLC (high-frequency PLC) performs at frequencies from $1.8-250 \mathrm{MHz}$ and it has higher data rate up to $200 \mathrm{Mbps}$ and shorter transmission distance than that of the NB-PLC. The PLCs can also be classified to PLC over alternative current (AC) lines and PLC over direct current (DC) lines depends on the type of the current carried by the power lines.

In PLCs systems, the transmitted data is firstly modulated by modem node then it is injected to the power lines, which represents the transmission medium, to be sent to its destination. At the receiver node, the information signal passes through a filtering process then a demodulation technique to recover the original data ${ }^{82}$. Different modulation techniques can be used with this technology such as, frequency shift keying (FSK), OFDM, binary phase shift keying (BPSK) and spread-FSK (SFSK). PLCs systems have been used for different applications such as, home automation, home networking, narrow-band PLC - Radio broadcasting and automotive 80 181. The NB-PLC systems have been generating widespread attention from academia and industries owing to its applications in different fields such as; home-control, the smart-grid, smart energy generation and micro-inverters.

The BB-PLC was initially used for home applications only, but recent studies have proved that this technology can fulfill the future requirements of smart-grid applications ${ }^{83}$. This technology has been also used in vehicles applications for the recent years ${ }^{9}$. Transmission data between the electronic parts of the vehicle such as sensors and actuators can be achieved by using its electrical wires network without any extra weight and $\operatorname{cost}^{84}$. Inside trains, the BB-PLC technology can be used for different purposes. In train entertainment can be provided to the commuter of the long-haul trips through the power line networks of the train. This technology can also distribute a high-speed internet to the commuters inside trains if the trains are connected to a proper communication network 9 . Passengers can check the trip information, order meals and make tickets booking using this on-board network. For safety and security reasons, cameras and other safety devices can be connected by the BB-PLC to monitor the train coaches. Furthermore, connecting the on-board electronic equipment with each other to share the important data ${ }^{84}$. Fig. 8 shows PLC and VLC systems within a train coach.

Due to the harsh transmission medium of the PLCs technology, a number of technical issues is associated. These power lines were firstly designed for current transmission only. First of all, the varying channel model, this is a huge variation in response between frequency, phase and amplitude of the signal. Furthermore, the transmission over such channel can be attenuated by the signal reflection due to the mismatching of the impedance of the electrical network because of its topology and physical properties. Therefore, one of the major issues is studying the transfer function of the PLCs and to find appropriate channel model which can perfectly represent it in computer simulations ${ }^{85}$. However, there are number of the channel models that can accurately model the transmission channel are proposed in the literature such as multi-path and two-port network models, the latter also know as ABCD matrix channel mode 86 867.

Transmission over PLCs is also affected by noise which is considered one of the most destructive issues in this technology. Noise over PLCs is categorized into two main categories namely, colored-background noise and impulsive noise. While the former varies slowly with time and remains stationary over some minutes and some time up to hours, the latter occurs randomly with short duration and high power spectral density (PSD) 88 . Although the impulsive noise has a short duration, it can severely

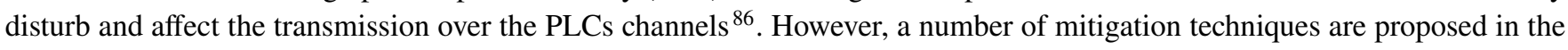




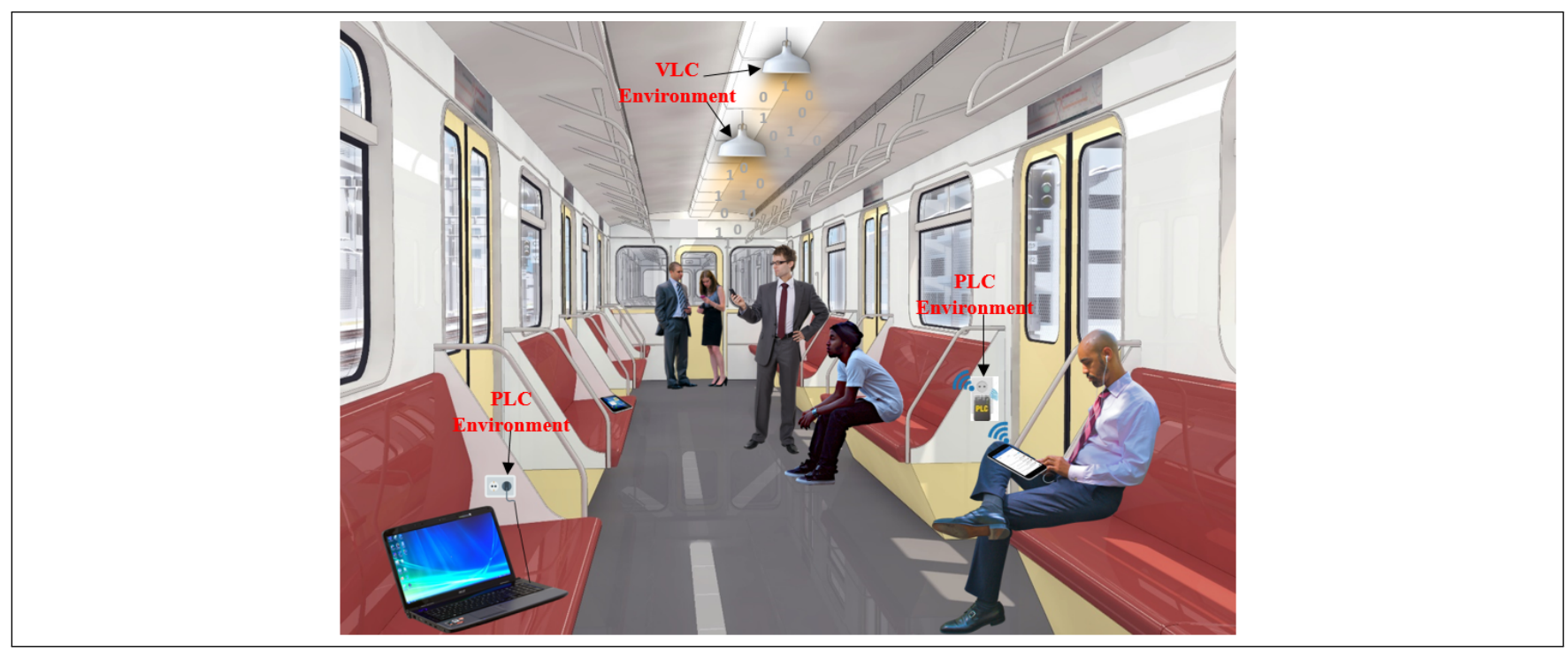

Fig. 8 PLC and VLC systems inside train.

literature for the purpose of mitigating this channel impairments. These include multi-carrier modulation (MCM), blanking nonlinearity, clipping non-linearity, hybrid blanking/clipping non-linearity, coding, multiple input multiple output (MIMO) and time and frequency domain (TFD) techniques 88 89190|91

The power cables radiate electrical signals to the surroundings when the information signals travel along the PLCs between the transmitter and the receiver ${ }^{92}$. This radiated signals can cause a malfunction to the nearby electronic equipment. This phenomena known as electromagnetic interference (EMI). Therefore, a number of standard bodies has set electromagnetic compatibility (EMC) standards to control both modes of the EMI, namely inductive and conductive, at acceptable level ensuring the reliability and the safety of the PLCs systems ${ }^{92193194}$. On top of the above issues, PLCs systems can not provide services to the end users at mobility. Therefore, combining PLCs systems with other communications systems such as, RF and VLCs can provide better mobility and performance to the end users ${ }^{78 \mid 65}$. However, the implementation of such hybrid systems can also tackle the networks coverage problems and increase the overall capacity of the systems. ${ }^{78 \mid 65}$.

\section{4 | Hybrid Communication Systems}

Reliable communication systems which can provide better network coverage, throughput and mobility to the train commuters can be one of the most critical issues in onboard communication system designing. This is due to the increase of the multimedia users in trains which means that single network on board might not be able to provide reliable services to the passengers. However, implementing hybrid communication systems, such as, PLC/VLC, PLC/RF and VLC/RF in indoor environments can improve the system performance and the user's QoS and provide better mobility to the end users ${ }^{78|72| 65}$. Since each network does not affect the coverage of the other networks as there is no interference between them, the total capacity of the hybrid system is better than that in the single system ${ }^{72}$. Relays such as amplify-and-forward (AF) and decode-and-forward (DF) are often used with the hybrid systems to increase the transmission distances and offer greater system throughput 6 (65)78.

Integrating networks is one of the most significant current discussions in indoor applications and has attracted both academia and industry ${ }^{78 / 65 \mid 72}$. The study in ${ }^{721}$ discusses the implementation of the hybrid Li-Fi/Wi-Fi network in indoor environments. The authors believe that the $300 \mathrm{THz}$ license-free used by the Li-Fi technology can be considered as a solution to the problem of limited availability of the radio frequency (RF) spectrum. The electromagnetic spectrum used by each one of these two technologies is totally different so they do not interfere with each other which enables the implementation of such a cooperative network ${ }^{72}$. The study proposed a dynamic load balancing (LB) to tackle the issue of the frequent handover between the LoSs of the LEDs during the movement of the end users. The Wi-Fi system provides services to the moving users and the static ones are served by the Li-Fi network. The authors concluded that the Li-Fi link provides higher data rate to the static users than that provided to the moving users by the Wi-Fi one ${ }^{72}$. 


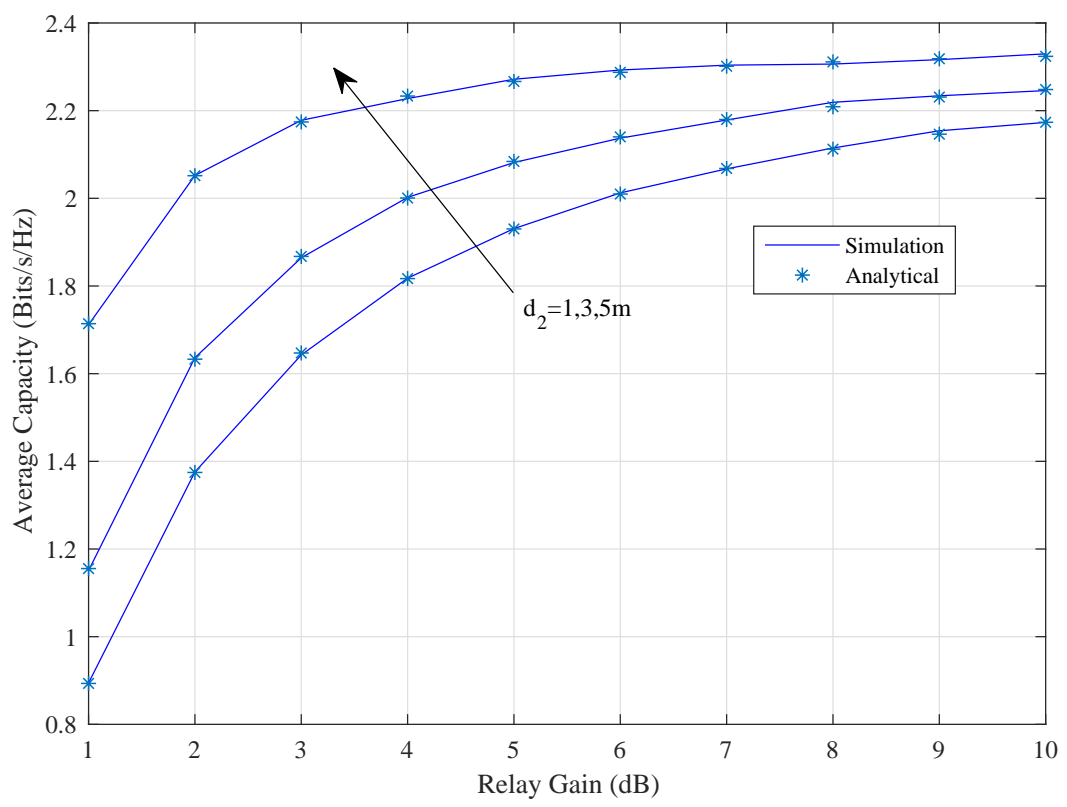

Fig. 9 Average capacity versus the relay gain for different values of relay-destination distance.

Using the Li-Fi technology as a complementary network to the RF one was investigated in 95 . The authors considered a cooperative VLC/RF down-link where the full coverage is provided by the RF network supported by the LoS of the LEDs. The authors indicated that the proposed cooperative system is capable of providing higher data rate than the single systems. It was also indicated that this system is able to overcoming some issues of the RF and Li-Fi networks such as limited availability of $\mathrm{RF}$ spectrum, the frequent handover of the $\mathrm{Li}$-Fi due to its small-coverage area and the Li-Fi network incapability of providing convenient Up-Link coverage ${ }^{95}$. From the context of that, the hybrid Li-Fi/Wi-Fi system can enhance the robustness and increase throughput, the authors of ${ }^{96}$ studied the cooperation between these two networks. The results of this study showed that the hybrid system performs much better than the WiFi one, especially in the crowded areas. It was also found that the VLC system can provide better performance than that provided by Wi-Fi system when the transmission distance is relatively small.

The advantage of utilizing the existing electrical network in indoor environments offers the opportunity to use PLCs system as back-hull for both RF and VLCs. The discussion regarding implementing hybrid PLC/RF started in the last decade where each network was considered working at a different time from the other. The proposed hybrid system was considered for vehicular and

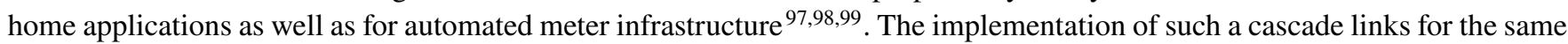
application was discussed in ${ }^{100 / 101}$, which considered that both networks are working simultaneously. The cooperative PLC/RF system was also discussed in different aspects and different system setups by 102103104 . Their conclusions can be summarized by that the hybrid PLC/RF can increase the throughput and enhance the performance of the system by offering better data rate to end users. This was also confirmed by our work in $\frac{78}{78}$ where we compared the performance of the hybrid PLC/RF with its counterpart in PLC only.

Several studies investigated the use of relays with the PLC, RF, and hybrid PLC/RF systems ${ }^{99 / 78 / 105 \mid 106 / 107}$. The studies involved different relaying protocols such as AF, DF, include incremental DF (IDF) and selective DF (SDF). The authors in ${ }^{108 \mid 109}$ indicated that optimizing the relay position on the network can offer better performance and improve the power consumption of the system. They also concluded that the use of relays can be more beneficial to the RF network than to the PLC one. We discussed the implementation of AF relay in hybrid PLC/RF network in $\frac{78}{7}$. The proposed system was investigated in terms of average capacity. The effect of some of the system parameter on its performance was studied. The results showed that the considered system can offer better performance and mobility to the end users. As it can be seen from Fig. 9 that the performance of the system can be improved by increasing the relay gain which justifies the use of the relay in the system.

Recently, PLC technology has been associated with the new technology VLCs. The advantage of using the pre-installed infrastructures of the power line networks for the PLCs and the LEDs for the VLCs makes the hybrid PLC/VLC system an attractive and cost-effective system. In the cooperative PLC/VLC system, the PLC is utilized as a backbone for the VLC which in turns transforms the electrical signal into an optical signal then deliver it to the users $\frac{110}{10}$. This hybrid system was first presented 


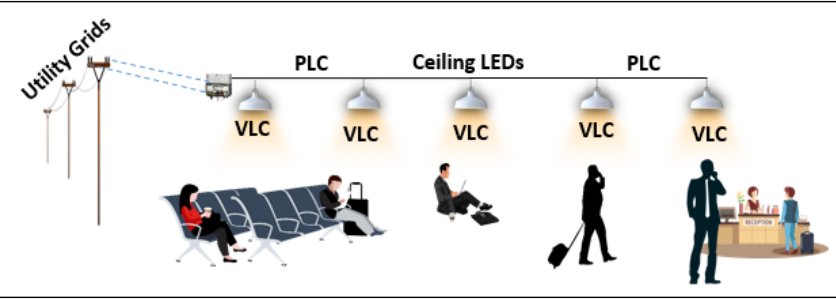

Fig. 10 A cooperative PLC/VLC system inside a train station.

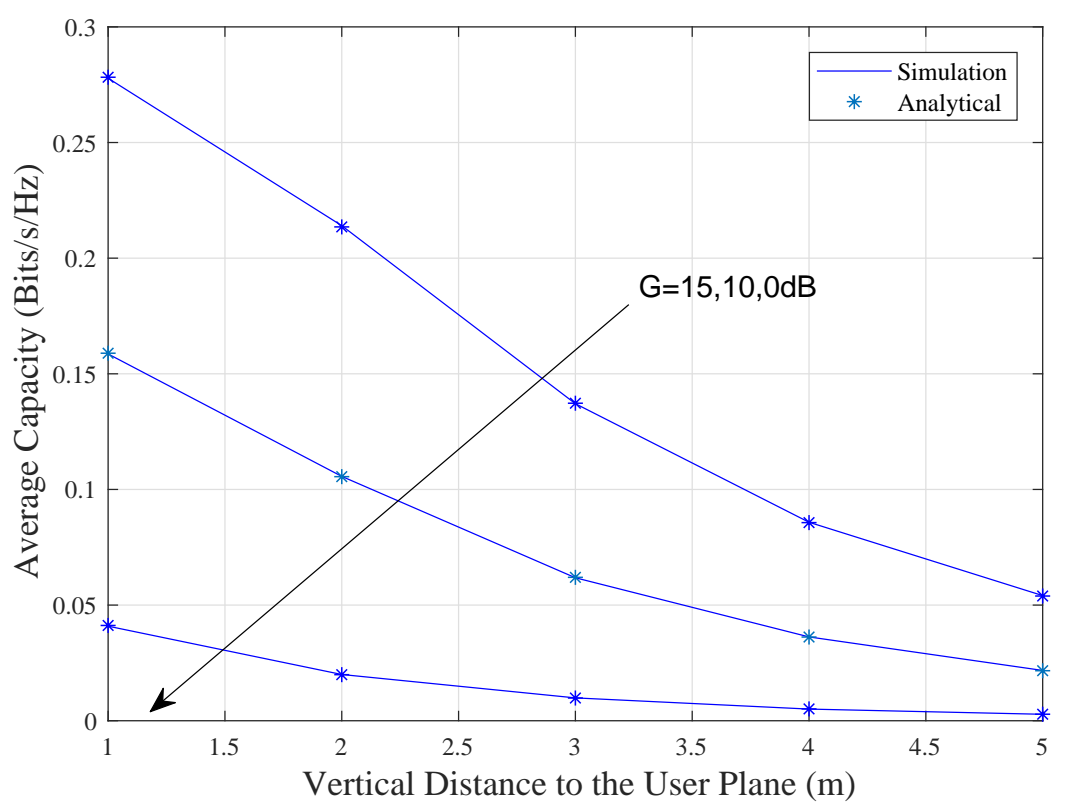

Fig. 11 Average capacity with respect to the vertical distance to the user plane for different values of the relay gain.

and discussed in 111 . The authors used the ubiquitous electricity power-lines as backbones the VLC technology which employs the ceiling white LEDs for indoor optical wireless. They concluded that such integration will play a crucial role in both indoor and outdoor applications. The main reason for this is that no new installations are required for the implementation of such a cascaded system. Furthermore, there is no need for demodulating the transmitted signal through the PLC which makes its deployment a very simple task 111 . Fig. 10 shows a cooperative PLC/VLC system inside train station.

Since then, this hybrid system has been investigated by many researchers in several aspects $111|112| 113|114| 65$. Motivated by adopting the concepts of the RF communications for the hybrid PLC/VLC system, the authors in ${ }^{[112}$ has investigated the implementation of MIMO and relaying techniques for this system. A novel and cost-effective scheme for the cooperative PLC/VLC was proposed in 113 . The results showed that the required modification to the current infrastructure is less than the other schemes and simplifies the complexity of the network protocol of VLC. Frequency-domain and time-domain schemes were proposed in $\sqrt{114}$ for the positioning purpose. The authors also considered a direct re-transmission concept in order to reduce the modifications to the origin network. In our study ${ }^{65}$ we discussed the implementation of AF relay with the PLC/VLC. The results of this study indicated that the performance of the system is negatively affected by the overall distance and it can be improved by increased the relay gain as shown in Fig. 11. It was also revealed that the proposed system performs better by increasing the input power as appears in Fig. 12 . 


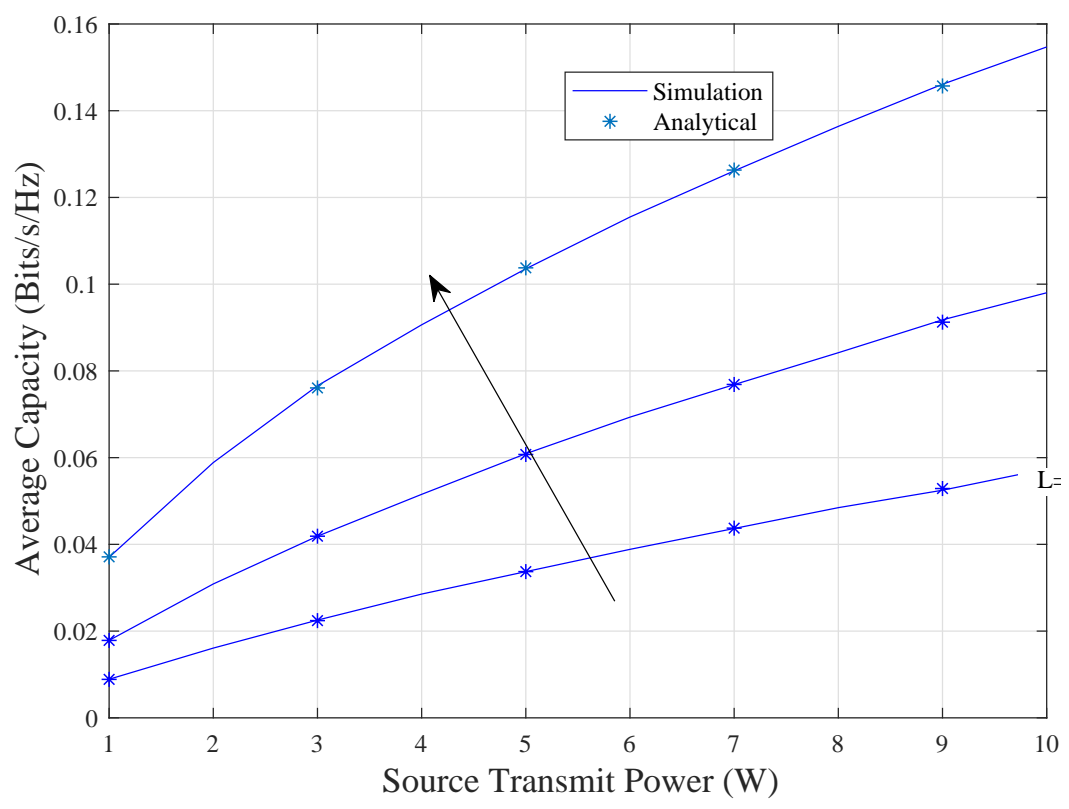

Fig. 12 Average capacity as a function of input power for different values of the vertical distance to the user plane.

\section{5 | FUTURE OF RAILWAY COMMUNICATIONS}

With the increase of video contents on the internet, most people prefer to remain glued to their smart gadgets while traveling. Most of the time, the speed of the internet plays the spoilsports. Due to this, consumers demand higher data rate and more reliable communication systems from service providers. This demand and for the commuters satisfaction will push the entire industry towards finding a proper candidate for communication systems that are mentioned above in this paper. The sixth-generation technology (6G) with its expected data rate of $1 \mathrm{Tbps}$ might be one of the candidates for the railway communication networks. The speeds of the mentioned systems are by far slower than the expected speed of this future technology. Thanks to its 100 GHz-to-1 THz high-frequency that 6G technology is predicted to play an essential role in different applications. This includes the Internet of Everything (IoE), robotics, autonomous drone delivery and transport systems 115 .

The outdoor wireless communication (OWC), which is known by free-space optical (FSO) communication, is used for highdata-rate communications between two antennas over a long distance. The available optical bandwidth of the FSO links is very high compared to its counterpart of the RF. Thanks to the very narrow laser beams used by the FSO that increases the overall system security and reduces the electromagnetic interference ${ }^{116] 117}$. FCO systems utilize unlicensed frequencies above $300 \mathrm{GHz}$. As a result, no license fee is required for the FSO system 118 . This technology is appealing for several applications such as backhaul for wireless links, medical data transmission, videos monitoring, etc.116. FSO systems can be installed as a complementary network to the current railway systems to cover their coverage holes, particularly in tunnels.

In our study 119 , we investigated using the overhead line equipment (OLE) as access network connecting trains to the backbone communication networks. These lines are used to deliver electricity from feeder substations to the trains so they could move. OLE falls under the medium-voltage transmission lines as it carries power electricity at $25 \mathrm{kV}$. The authors believe that medium-voltage power line communication (MV-PLC) can provide reliable transmission and is a key technology for the last-mile communication. The authors developed a two-port network model to represent the channel transfer function of the OLE using the transmission lines theory. Different channel scenarios were involved to investigate the OLE channel and to study the effect of different channel parameters (e.g., the channel length and the transmission frequency) on the performance of the transmission.

One of the scenarios which were studied in this study is the impact of the train moving away from the railway substation at different speeds. The train starts with steady-state then accelerates from speed zero up-to $80 \mathrm{Km} / \mathrm{h}$ in 5 minutes time. Then it continuous its $80 \mathrm{Km} / \mathrm{h}$ speed for 10 minutes before it starts to decelerate for 5 minutes from its current speed until it totally stops at the next train stop. Movement equations are used to calculate the train acceleration and to update the train position which represents the length of the channel. The results showed that both the length of OLE and the frequency have a negative 


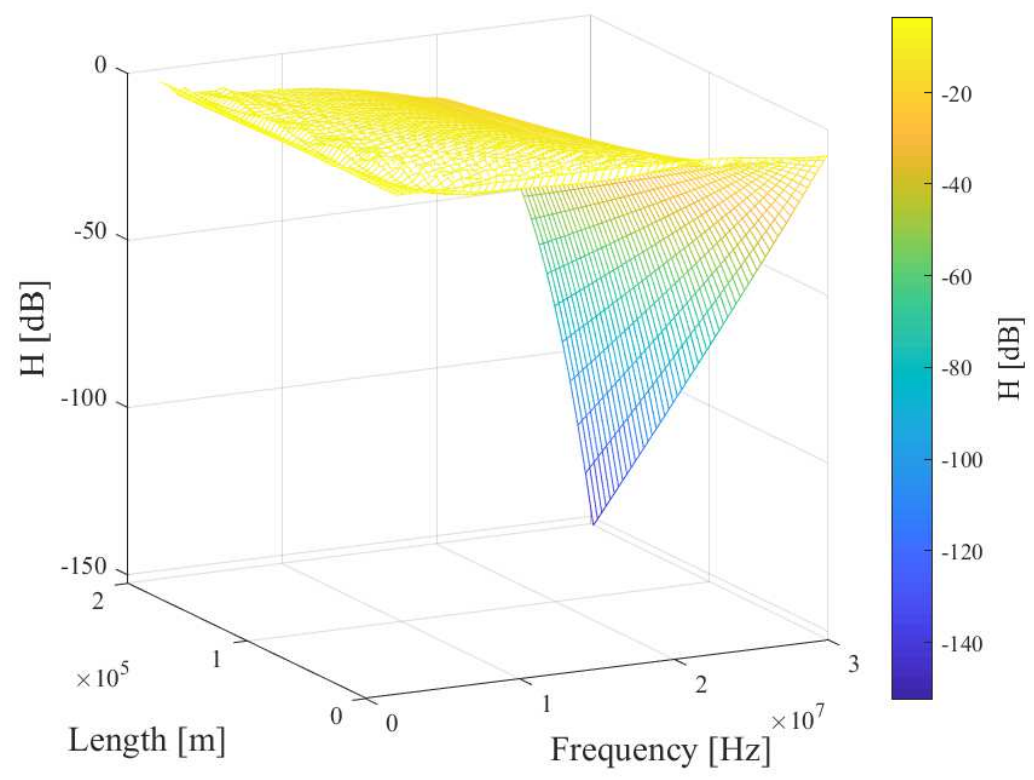

Fig. 13 A 3D surface plot for the channel response as a function of frequency and line length.

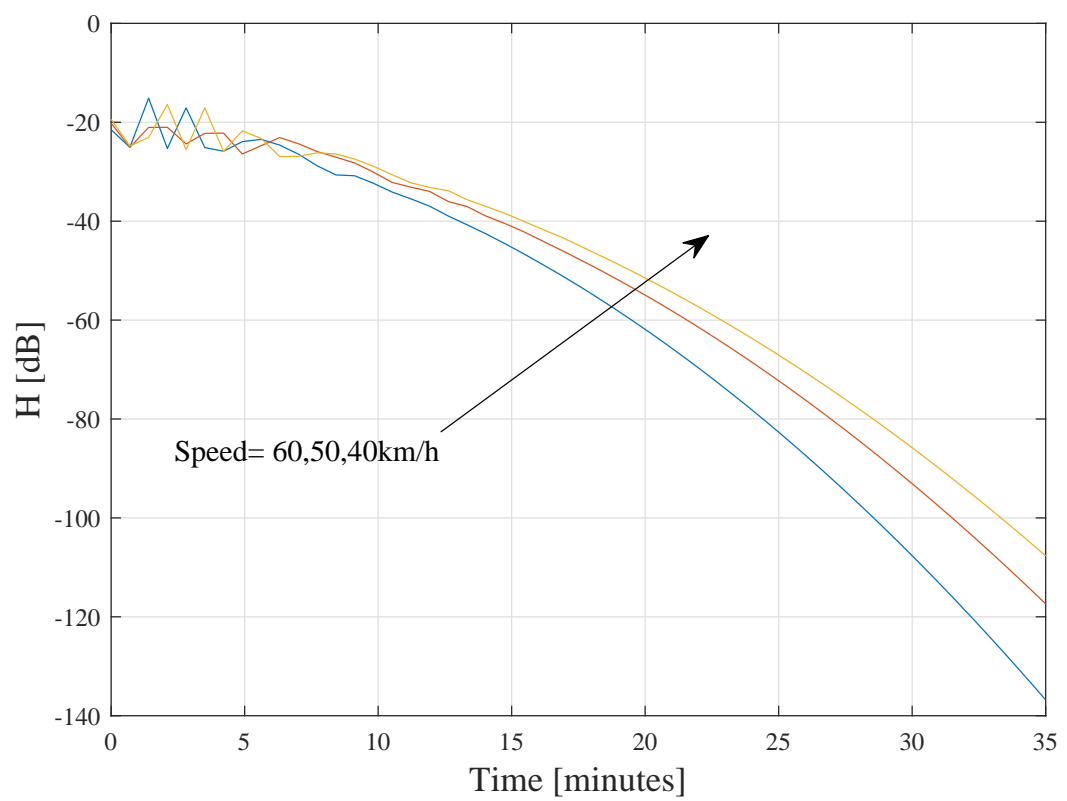

Fig. 14 Channel transfer function with respect to time traveling for different train speeds.

impact on the transmission as it was clear that the transmission is less attenuated at lower frequencies and shorter distances. We also found that the transmission is negatively affected the speed of the train see Figs. 13 and 14

\section{6 | CONCLUSION}

The HSR has been positioned as a solution to current intercity transportation, offering new perspective and using novel technologies to address current and future problems facing the mobility sector. This is expected to attract more commuters and 
consequently increase profitability. However, the growth of railway demand and its development require a reliable communication system to meet users satisfaction. This paper provided a survey of potential HSR-communication systems and the challenges of the current communication system. We showed that the LTE-R, which is a special configuration of the public network LTE, has the ability to fulfil the current HSR requirements. Having said that, we noted that, the need for a system that is more reliable than LTE-R is inevitable. We presented an overview of inside train communication, the advantages and disadvantages of onboard distribution systems, and posited that hybrid systems provide more reliable services to the train commuters compared to the services provided by the single ones.

\section{7 | ACKNOWLEDGEMENT}

This research has been jointly funded by OSL Rail Ltd, and the Faculty of Science and Engineering, Manchester Metropolitan University, UK.

\section{Data Availability Statement}

Data sharing is not applicable to this article as no datasets were generated or analysed during the current study.

\section{Financial disclosure}

This research is funded by OSL LTD.

\section{Conflict of interest}

The authors declare no conflict of interest.

\section{References}

1. Clark S. A history of railway signalling: From the bobby to the balise. In: ; 2010: 7-20

2. He R, Ai B, Wang G, et al. High-Speed Railway Communications: From GSM-R to LTE-R. IEEE Vehicular Technology Magazine 2016; 11(3): 49-58. doi: 10.1109/MVT.2016.2564446

3. Lofmark DTN, McKavanagh M. Survey on operational communications-study for the evolution of the railway communications system. In: ; 2014.

4. Barbu G. Broadband communication with moving trains, technology state of the art. In: ; 2010.

5. Masur KD, Mandoc D. LTE/SAE the future railway mobile radio system: Long-term vision on railway mobile radio technologies. In: ; 2009.

6. Kastell K. Communication to and in trains. In: ; 2015: 1-4

7. Uhlirz M. Adapting GSM for use in high-speed railway networks. Dissertation, Technische University Wien, 1995. 1995.

8. Ndjiongue AR, Ferreira H. Power Line Communications (PLC) Technology: More Than 20 Years of Intense Research. Transactions on Emerging Telecommunications Technologies 2019: 1-20. doi: 10.1002/ett.3575

9. Barmada S, Gaggelli A, Musolino A, Rizzo R, Raugi M, Tucci M. Design of a PLC system onboard trains: Selection and analysis of the PLC channel. In: ; 2008: 13-17

10. Russo D, Gatti A, Ghelardini A, et al. Power Line Communication : a new approach for Train Passenger Information Systems. In: ; 2008. 
11. Becsi T, Aradi S, Gaspar P. Using train interconnection for intra-train communication via CAN. Acta Polytechnica Hungarica 2015; 12(4): 27-38.

12. Ahamed S. Visible light communication in railways. In: ; 2016: 1-5

13. Saadi M, Ahmad T, Saleem MK, Wuttisittikulkij L. Visible light communication - An architectural perspective on the applications and data rate improvement strategies. Transactions on Emerging Telecommunications Technologies 2018. doi: 10.1002/ett.3436

14. Cailean AM, Cagneau B, Chassagne L, Popa V, Dimian M. A survey on the usage of DSRC and VLC in communicationbased vehicle safety applications. In: ; 2014: 69-74

15. Renner M, Gardner G. Global competitiveness in the rail and transit industry. Worldwatch Inst., Washington, DC, USA, 2010. 2010.

16. Sector overview and competitiveness survey of the railway supply industry. European Comm., Rotterdam, The Netherlands, 2012.

17. The UNIFE world rail market study âĂ $̈$ forecast 2014 to 2019. UNIFE,Brussels, Belgium, Tech. Rep., 2014. 2014.

18. Sullivan. F. Strategic Analysis of Communication Based Train Control Systems in the Western European Urban Rail Market.. Online 2013.

19. Farooq J, Soler J. Radio Communication for Communications-Based Train Control (CBTC): A Tutorial and Survey. IEEE Communications Surveys Tutorials 2017; 19(3): 1377-1402. doi: 10.1109/COMST.2017.2661384

20. 2016 tTGRMN. UNIFE Study Key Findings \& Future Outlook. UNIFE, Brussels, Belgium, 2008. 2008.

21. The signalling programme-A total renewal of the Danish signalling infrastructure. Banedanmark, Copenhagen, Denmark, Tech. Rep., 2010. 2010.

22. Worldwide rail market study-Status quo and outlook 2016. UNIFE,Brussels, Belgium, Tech. Rep., 2008. 2008.

23. Alvarez R, Roman J. ETCS L2 and CBTC over LTE-Convergence of the radio layer in advanced train control systems. Proc. IRSE Inst. Railway Signal Eng. Tech. Meeting, 2013 2013: 1-12.

24. MartÃnnez BM. ERTMS CBTC technology convergence. presented at MetroRail, Madrid, Spain, 20132013.

25. Benefits and barriers to CBTC and ETCS convergence. Proc. MetroRail Conf., London, U.K.,2012. 2012.

26. Farooq J, Bro L, Karstensen RT, Soler J. Performance Evaluation of a Multi-radio, Multi-hop Ad-hoc Radio Communication Network for Communications-Based Train Control (CBTC). IEEE Transactions on Vehicular Technology 2018; 67(1): 56-71. doi: 10.1109/TVT.2017.2777874

27. Mishra A, Shin M, Arbaugh W. An empirical analysis of the IEEE 802.11 MAC layer handoff process. 2003; 33.

28. Jiang H, Zhao H, Zhao B. A novel handover scheme in wireless LAN in CBTC system. In: ; 2011: 473-477

29. Theeg G, Vlasenko S. Railway Signalling and Interlocking. Hamburg, Germany: Eurailpress, 2009. 2009.

30. Pascoe RD, Eichorn TN. What is communication-based train control?. IEEE Vehicular Technology Magazine 2009; 4(4): 16-21. doi: 10.1109/MVT.2009.934665

31. Shan Q, Wen Y. Research on the BER of the GSM-R communications provided by the EM transient interferences in High-Powered Catenary System Environment. In: ; 2010: 757-760

32. Cao Y, Cai B, Tang T, Mu J. Reliability Analysis of CTCS Based on Two GSM-R Double Layers Networks Structures. In: . 3. ; 2009: 242-246

33. Zhong Z. Dedicated Mobile Communications for High-speed Railway, Advances in High-speed Rail Technology. In: ; 2018 
34. Jie S, Xiaojin Z, Tingting G. Performance analysis of GSM-R network structure in China train control system. In: . 2. ; 2010: V2-214-V2-218

35. Cheng M, Fang X, Luo W. Beamforming and positioning-assisted handover scheme for long-term evolution system in high-speed railway. IET Communications 2012; 6(15): 2335-2340. doi: 10.1049/iet-com.2011.0313

36. Xiang Z, Yang F. A novel handover scheme with relay technique in GSM-R network. In: ; 2009: 1-4

37. Du H, Wen C, Li W. A new method for detecting and early-warning in-band interference of the GSM-R network. In: ; 2017: 800-804

38. Midya S, Bormann D, Schutte T, Thottappillil R. Pantograph Arcing in Electrified Railways-Mechanism and Influence of Various Parameters-Part I: With DC Traction Power Supply. IEEE Transactions on Power Delivery 2009; 24(4): 19311939. doi: 10.1109/TPWRD.2009.2021035

39. Dudoyer S, Deniau V, Adriano R, et al. Study of the Susceptibility of the GSM-R Communications Face to the Electromagnetic Interferences of the Rail Environment. IEEE Transactions on Electromagnetic Compatibility 2012; 54(3): 667-676. doi: 10.1109/TEMC.2011.2169677

40. Pous M, Azpurua MA, Silva F. Measurement and Evaluation Techniques to Estimate the Degradation Produced by the Radiated Transients Interference to the GSM System. IEEE Transactions on Electromagnetic Compatibility 2015; 57(6): 1382-1390. doi: 10.1109/TEMC.2015.2472983

41. Beckman C, Nilsson K. The Technical and Economic Consequences of Protecting GSM-R in Sweden. In: ; 2016: 1-6

42. Branly P, Wireless S. GSM-R IG : Solutions against Interferences from Public operators. In: ; 2016.

43. Zayas AD, Perez CAG, Gomez PM. Third-Generation Partnership Project Standards: For Delivery of Critical Communications for Railways. IEEE Vehicular Technology Magazine 2014; 9(2): 58-68. doi: 10.1109/MVT.2014.2311592

44. Ruesche SF, Steuer J, Jobmann K. The European Switch. IEEE Vehicular Technology Magazine 2008; 3(3): 37-46. doi: 10.1109/MVT.2008.927490

45. Sniady A, Soler J. An overview of GSM-R technology and its shortcomings. In: ; 2012: 626-629

46. Hcine M, Bouallegue R. On the dimensioning of LTE and LTE-advanced networks. Transactions on Emerging Telecommunications Technologies 2015; 28. doi: 10.1002/ett.2957

47. Ibrahim EA, Rizk MRM, Badran EF. Study of LTE-R X2 handover based on A3 event algorithm using MATLAB. In: ; 2015: 1155-1159

48. Sniady A, Soler J. Capacity gain with an alternative LTE railway communication network. In: ; 2014: 54-58

49. Calle-Sanchez J, Molina-Garcia M, Alonso JI, Fernandez-Duran A. Long term evolution in high speed railway environments: Feasibility and challenges. Bell Labs Technical Journal 2013; 18(2): 237-253. doi: 10.1002/bltj.21615

50. Vinel A. 3GPP LTE Versus IEEE 802.11p/WAVE: Which Technology is Able to Support Cooperative Vehicular Safety Applications?. IEEE Wireless Communications Letters 2012; 1(2): 125-128. doi: 10.1109/WCL.2012.022012.120073

51. Choi J, Cho H, Oh H, et al. Challenges of LTE high-speed railway network to coexist with LTE public safety network. In: ; 2015: 543-547

52. Ai B, Cheng X, KÃijrner T, et al. Challenges Toward Wireless Communications for High-Speed Railway. IEEE Transactions on Intelligent Transportation Systems 2014; 15(5): 2143-2158. doi: 10.1109/TITS.2014.2310771

53. Mazzenga F, Giuliano R, Neri A, Rispoli F. Integrated Public Mobile Radio Networks/Satellite for Future Railway Communications. IEEE Wireless Communications 2017; 24(2): 90-97. doi: 10.1109/MWC.2016.1500266WC

54. Shah SAA, Ahmed E, Imran M, Zeadally S. 5G for Vehicular Communications. IEEE Communications Magazine 2018; 56(1): 111-117. doi: 10.1109/MCOM.2018.1700467 
55. Hong S, Brand J, Choi JI, et al. Applications of self-interference cancellation in 5G and beyond. IEEE Communications Magazine 2014; 52(2): 114-121. doi: 10.1109/MCOM.2014.6736751

56. Hemadeh IA, Satyanarayana K, El-Hajjar M, Hanzo L. Millimeter-Wave Communications: Physical Channel Models, Design Considerations, Antenna Constructions, and Link-Budget. IEEE Communications Surveys Tutorials 2018; 20(2): 870-913. doi: 10.1109/COMST.2017.2783541

57. Ahamed MM, Faruque S. Propagation factors affecting the performance of 5G millimeter wave radio channel. In: ; 2016: 0728-0733

58. Taneja M. A resource management framework for LTE-WLAN networks in high-speed trains. In: ; 2016: 155-160

59. Liang X, Ong FLC, Chan PML, Sheriff RE, Conforto P. Mobile Internet access for high-speed trains via heterogeneous networks. In: . 1. ; 2003: 177-181 Vol.1

60. Briso-Rodriguez C, Guan K, Xuefeng Y, KÃijrner. T. Wireless Communications in Smart Rail Transportation Systems.. J. Wireless Communications and Mobile Computing. 2017(10). doi: 10.1155/2017/6802027 Download citation as E

61. Goth G. New Wi-Fi Technology Racing Past Standards Process. IEEE Distributed Systems Online 2008; 9(10): 1-1. doi: 10.1109/MDSO.2008.29

62. Masson É, Berbineau M. Railway Applications Requiring Broadband Wireless Communicationsch. 2: 35-79; Cham: Springer International Publishing . 2017

63. Urushihara T, Takahashi $\mathrm{H}$, Kobayashi M, et al. $60 \mathrm{GHz}$ wireless technologies for WiGig/IEEE 802.11ad multi-gigabit systems. In: ; 2014: 628-630.

64. Kalfas G, Pleros N, Alonso L, Verikoukis C. Network planning for 802.11 ad and MT-MAC $60 \mathrm{GHz}$ fiber-wireless gigabit wireless local area networks over passive optical networks. IEEE/OSA Journal of Optical Communications and Networking 2016; 8(4): 206-220. doi: 10.1364/JOCN.8.000206

65. Gheth W, Rabie KM, Adebisi B, Ijaz M, Harris G. Performance Analysis of Integrated Power-Line/Visible-Light Communication Systems with AF Relaying. In: ; 2018.

66. Che Z, Fang J, Jiang ZL, Yu X, Xi G, Chen Z. A physical-layer secure coding scheme for visible light communication based on polar codes. In: ; 2017: 1-2

67. Khan SM, Saha N, Rahman MR, Hasan M, Rahman MS. Performance improvement of MIMO VLC using V-BLAST technique. In: ; 2016: 45-49

68. Fan L, Liu Q, Jiang C, et al. Visible light communication using the flash light LED of the smart phone as a light source and its application in the access control system. In: ; 2016: 1-4

69. Wei-Keng L, Chen S, Chen-I C, Tsai Y. The analysis of the thermal resistance structure of LEDs by measuring its transient temperature variation. In: ; 2013: 214-217

70. Das S, Chakraborty A, Chakraborty D, Moshat S. PC to PC data transmission using visible light communication. In: ; 2017: $1-5$

71. Siddiqi K, Raza AD, Muhammad SS. Visible light communication for V2V intelligent transport system. In: ; 2016: 1-4

72. Wang Y, Haas H. Dynamic Load Balancing With Handover in Hybrid Li-Fi and Wi-Fi Networks. Journal of Lightwave Technology 2015; 33(22): 4671-4682. doi: 10.1109/JLT.2015.2480969

73. Niaz MT, Imdad F, Mehmood K, Kim HS. A study of indoor VLC system based on TLS receiver. Transactions on Emerging Telecommunications Technologies 2018. doi: 10.1002/ett.3479

74. Chatterjee S, Sabui D. Daylight integrated indoor VLC architecture: An energyâĂ ̌̌efficient solution. Transactions on Emerging Telecommunications Technologies 2019. doi: 10.1002/ett.3800 
75. Chi N, Shi J. Investigation on overlapping interference on VLC networks consisting of multiple LEDs. ICT Express 2015; 1. doi: $10.1016 /$ j.icte.2015.09.004

76. Sheoran S, Garg P, Sharma P. Interference Mitigation Technique with Coverage Improvement in Indoor VLC System. Transactions on Emerging Telecommunications Technologies 2018; 30. doi: 10.1002/ett.3511

77. O’Brien DC, Zeng L, Le-Minh H, Faulkner G, Walewski JW, Randel S. Visible light communications: Challenges and possibilities. In: ; 2008: 1-5

78. Gheth W, Rabie KM, Adebisi B, Ijaz M, Harris G, Alfitouri A. Hybrid Power-Line/Wireless Communication Systems For Indoor Applications. In: ; 2018: 1-6

79. Capponi L, FernÃąndez I, Roggo D, Arrinda A, Angulo I, Vega DDL. Comparison of Measurement Methods of Grid Impedance for Narrow Band-PLC up to $500 \mathrm{kHz}$. In: ; 2018: 1-6

80. Rehman uA, Bashir N, Hassan NU, Yuen C. Impact of home appliances on the performance of narrow-band power line communications for smart grid applications. In: ; 2016: 3511-3514

81. Galli S, Scaglione A, Wang Z. For the Grid and Through the Grid: The Role of Power Line Communications in the Smart Grid. Proc. IEEE 2011; 99(6): 998-1027. doi: 10.1109/JPROC.2011.2109670

82. Ginot N, Mannah MA, Batard C, Machmoum M. Application of Power Line Communication for Data Transmission Over PWM Network. IEEE Transactions on Smart Grid 2010; 1(2): 178-185. doi: 10.1109/TSG.2010.2053225

83. Graf N, Tsokalo I, Lehnert R. Validating broadband PLC for smart grid applications with field trials. In: ; 2017: 497-502

84. Carrion MO, Lienard M, Degauque P. Communication over Vehicular DC Lines: Propagation Channel Characteristics. In: ; 2006: 2-5

85. Familua AD, Ogunyanda K, Swart TG, Ferreira HC, Olst RV, Cheng L. Narrowband PLC channel modeling using USRP and PSK modulations. In: ; 2014: 156-161

86. Zimmermann M, Dostert K. A multipath model for the powerline channel. IEEE Trans. Commun. 2002; 50(4): 553-559. doi: $10.1109 / 26.996069$

87. Peres P, Souza dCR, Bonatti IS. ABCD Matrix: A unique tool for linear two-wire transmission line modelling. Int. J. Elect. Eng. Educ 2003; 40(3): 220-229.

88. Gheth W, Rabie KM, Adebisi B. Impulsive Noise Modeling and Cancellation Strategies Over Power Line Channels. In: Boyaci A, Ekti AR, Aydin MA, Yarkan S., eds. Int. Telecommun. Conf.Springer Singapore; 2018; Singapore: 163-175.

89. Rabie KM, Alsusa E. Performance analysis of adaptive hybrid nonlinear preprocessors for impulsive noise mitigation over power-line channels. In: ; 2015: 728-733

90. Rabie KM, Alsusa E. Effective Noise Cancellation Using Single-Carrier FDMA Transmission in Power-Line Channels. IEEE Transactions on Power Delivery 2014; 29(5): 2110-2117. doi: 10.1109/TPWRD.2013.2297232

91. Rabie KM, Alsusa E. Improving blanking/clipping based impulsive noise mitigation over powerline channels. In: ; 2013: 3413-3417

92. Gheth W, Rozman M, Rabie KM, Adebisi B. EMC Measurements in Indoor Power Line Communication Environments. In: Boyaci A, Ekti AR, Aydin MA, Yarkan S., eds. Int. Telecommun. Conf.Springer Singapore; 2018; Singapore: 189-200.

93. Adebisi B, Honary B. Comparisons of Indoor PLC Emissions Measurement Results and Regulation Standards. In: ; 2006: 319-324

94. Adebisi B, Stott J, Honary B. Experimental study of the interference of PLC transmission power levels on HF bands. In: IEEE; 2006: 326-330. 
95. Li X, Zhang R, Hanzo L. Cooperative Load Balancing in Hybrid Visible Light Communications and WiFi. IEEE Transactions on Communications 2015; 63(4): 1319-1329. doi: 10.1109/TCOMM.2015.2409172

96. Shao S, Khreishah A, Ayyash M, et al. Design and analysis of a visible-light-communication enhanced WiFi system. IEEE/OSA Journal of Optical Communications and Networking 2015; 7(10): 960-973. doi: 10.1364/JOCN.7.000960

97. Holden T, Yazdani J. Hybrid security for hybrid vehicles exploring smart grid technology, powerline and wireless communication. In: ; 2011: 1-5

98. Cataliotti A, Cosentino V, Cara DD, et al. Experimental evaluation of an hybrid communication system architecture for Smart Grid applications. In: ; 2015: 96-101

99. M. B. A. Dib dL, Fernandes V, L. Filomeno dM, Ribeiro MV. Hybrid PLC/Wireless Communication For Smart Grids and Internet of Things Applications. IEEE Internet Things. J 2017; PP(99): 1-1.

100. Mafra J, Hosami M, Freitas L, Martinelli M, Almeida A. Hybrid communication module - motivations, requirements, challenges and implementations. In: ; 2015: 25-29

101. Lai SW, Messier GG. Using the Wireless and PLC Channels for Diversity. IEEE Transactions on Communications 2012; 60(12): 3865-3875. doi: 10.1109/TCOMM.2012.081512.110408

102. Sayed M, Tsiftsis TA, Al-Dhahir N. On the Diversity of Hybrid Narrowband-PLC/Wireless Communications for Smart Grids. IEEE Transactions on Wireless Communications 2017; 16(7): 4344-4360. doi: 10.1109/TWC.2017.2697384

103. Lai SW, Messier GG. The Wireless/Power-Line Diversity Channel. In: ; 2010: 1-5

104. Mathur A, Bhatnagar MR, Panigrahi BK. Performance of a dual-hop wireless-powerline mixed cooperative system. In: ; 2016: 401-406

105. Rabie KM, Adebisi B, Gacanin H, Nauryzbayev G, Ikpehai A. Performance evaluation of multi-hop relaying over nonGaussian PLC channels. J. Commun. Netw. 2017; 19(5): 531-538. doi: 10.1109/JCN.2017.000084

106. Tonello AM, Versolatto F, D’Alessandro S. Opportunistic Relaying in In-Home PLC Networks. In: ; 2010: 1-5

107. Alfitouri A, Hamdi KA. Multiple-Access Capabilities of a Common Gateway. IEEE Trans. Veh. Technol. 2017; 66(6): 5148-5159. doi: 10.1109/TVT.2016.2627810

108. D'Alessandro S, Tonello AM. On rate improvements and power saving with opportunistic relaying in home power line networks. EURASIP J. Advances. Signal Process. 2012; 2012(1): 194. doi: 10.1186/1687-6180-2012-194

109. Zou H, Chowdhery A, Jagannathan S, Cioffi JM, Masson JL. Multi-User Joint Subchannel and Power Resource-Allocation for Powerline Relay Networks. In: ; 2009: 1-5

110. Nlom SM, Ndjiongue AR, Ouahada K. Cascaded PLC-VLC Channel: An Indoor Measurements Campaign. IEEE Access 2018; 6: 25230-25239. doi: 10.1109/ACCESS.2018.2831625

111. Komine T, Nakagawa M. Integrated system of white LED visible-light communication and power-line communication. IEEE Transactions on Consumer Electronics 2003; 49(1): 71-79. doi: 10.1109/TCE.2003.1205458

112. Ma H, Lampe L, Hranilovic S. Integration of indoor visible light and power line communication systems. In: ; 2013: 291-296

113. Song J, Ding W, Yang F, Yang H, Yu B, Zhang H. An Indoor Broadband Broadcasting System Based on PLC and VLC. IEEE Transactions on Broadcasting 2015; 61(2): 299-308. doi: 10.1109/TBC.2015.2400825

114. Ma X, Ding W, Yang F, Yang H, Song J. A positioning compatible multi-service transmission system based on the integration of VLC and PLC. In: ; 2015: 480-484

115. Guan K, Li G, KÃijrner T, et al. On Millimeter Wave and THz Mobile Radio Channel for Smart Rail Mobility. IEEE Transactions on Vehicular Technology 2017; 66(7): 5658-5674. doi: 10.1109/TVT.2016.2624504 
116. Khalighi MA, Uysal M. Survey on Free Space Optical Communication: A Communication Theory Perspective. IEEE Communications Surveys Tutorials 2014; 16(4): 2231-2258. doi: 10.1109/COMST.2014.2329501

117. Niaz A, Qamar F, Ali M, Farhan R, Islam M. Performance analysis of chaotic FSO communication system under different weather conditions. Transactions on Emerging Telecommunications Technologies 2018; 30: e3486. doi: 10.1002/ett.3486

118. Chan VWS. Free-Space Optical Communications. J. Lightwave Technol. 2006; 24(12): 4750-4762.

119. Gheth W, Rabie KM, Adebisi B, Ijaz M, Harris G. Channel Modeling for Overhead Line Equipment for Train Communication. In: ; 2020. 


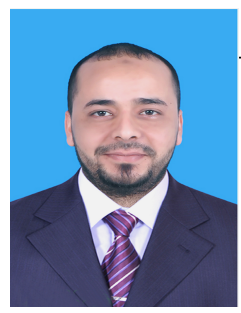

Waled Gheth. was born in Alkhomos, Libya in 1980. Received the B.Sc. in electrical and electronic engineering from Almergeb University, Alkhomos, Libya, in 2003. Received the M.Sc. Degree from Manchester Metropolitan University in Industrial Communication and Automation, in 2017. After the successful completion of his M.Sc., he has been awarded Manchester Metropolitan University studentship to pursue his Ph.D. in communication engineering. His research interests include signal processing and analysis of power-line, visible-light and wireless communication networks for indoor applications.

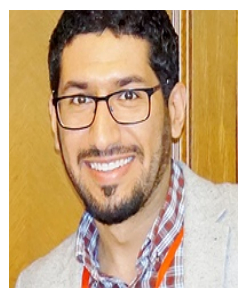

Khaled M. Rabie. received the Ph.D. degree in electrical and electronic engineering from the University of Manchester, UK, in 2015, and is currently an assistant professor with the department of Engineering at the Manchester Metropolitan University (MMU), U.K. He has worked as a part of several large-scale industrial projects and has published 100+ journal and conference papers (mostly IEEE). His primary research focuses on various aspects of the next-generation wireless communication systems. He serves regularly on the Technical Program Committee (TPC) of several major IEEE conferences, such as GLOBECOM, ICC, and VTC. Khaled has received numerous awards over the past few years in recognition of his research contributions including the Best Student Paper Award at the IEEE ISPLC (TX, USA, 2015), the MMU Outstanding Knowledge Exchange Project award of 2016, as well as the IEEE ACCESS Editor of the month award for August 2019. He serves as an Editor for IEEE COMMUNICATIONS LETTERS, an Associate Editor for IEEE ACCESS, an Area Editor for PHYSICAL COMMUNICATIONS, and an Executive Editor for the TRANSACTIONS on EMERGING TELECOMMUNICATIONS TECHNOLOGIES. Khaled is also a Fellow of the U.K. Higher Education Academy (FHEA).

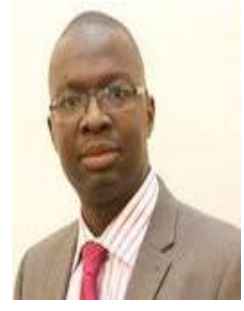

Bamidele Adebisi. (SM'15) is a full professor of intelligent infrastructure systems at the Metropolitan University, Manchester, UK. He received masters degree in advanced mobile communication engineering and Ph.D. in communication systems from Lancaster University, UK, in 2003 and 2009, respectively. He has worked on several commercial and government projects focusing on various aspects of smart infrastructure systems. He is particularly interested in collaborative research and development of technologies for electrical energy monitoring/management, transport, water, home automation, IoTs, Cyber Physical Systems and critical infrastructures protection. He is a Chartered Engineer, member of IET and a senior member of IEEE.

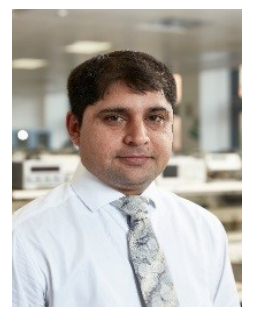

Muhammad Ijaz. has received his M.Sc. in Optoelectronic and Communication Engineering degree with commendation from Northumbria University at Newcastle upon Tyne, UK in 2009. After the successful completion of his M.Sc., he has been awarded Northumbria University studentship to pursue his Ph.D. He was awarded his PhD degree in 2013 at the same Northumbria University, UK for his research work in Free-Space Optical (FSO) Communications. He also worked as Research Fellow in Visible Light Communication at University of Edinburgh, UK between 2013-15. He worked in modelling and designing a large scale multipleinput multiple-output (MIMO) based visible light communication (VLC) system using spatial modulation and for novel methods of energy harvesting ideas in the field of wireless communications. Muhammad Ijaz is currently working as a lecturer at Manchester Metropolitan University, UK from 2015. His specialized areas of research and interests are optical wireless/fibre communications, advanced modulation schemes including OFDM, Visible light communication, applications of $\mathrm{LiFi}$, powerline communications, IoTs and photonics and optical sensors design. He is a member of IET and a member of IEEE.

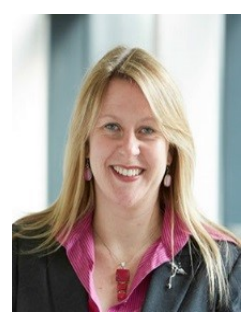

Georgina Harris. Dr Georgina Diane Harris MEng (Hons), MBA, EngD, CEng, FIMechE, MIET, MInstP, FRAS, FHEA. Georgina is Chair of the Recruitment and Admissions Committee of the Engineering Professors' Council. Georgina is the Greater Manchester Area Chair and Fellow of the Institution of Mechanical Engineers, a member of the Institution of Engineering and Technology, a member of the Institute of Physics, a Fellow of the Royal Astronomical Society and a Fellow of the Higher Education Academy. Georgina was a founder member and is a current governor of the Crewe Engineering and Design University Technical College and an academic at the Open University. Georgina has previously held the post of Head of School at Manchester Metropolitan University, Site Engineer and Power Specialist for the Square Kilometre Array Program Development Office (SPDO) and the SKA Support Engineer at the new Square Kilometre Array (SKA) Organisation. Georgina held the roles of PrepSKA UK Project Manager (October 2009 to December 2010) and SKADS System Design and Team Leader (October 2006 to September 2009) responsible for the production of the UK SKA demonstrator, 2-PAD (2 Polarisations All Digital) at Jodrell Bank Observatory in Cheshire. She is a Chartered Mechanical Engineer with an Engineering Doctorate, a 
Masters Degree in Mechanical Engineering and a Masters Degree in Business Administration. Georgina has worked in a number of academic-industrial collaboration projects. Her successes to date include the development of a combined particulate and NOx reduction technology for treatment of diesel exhaust gases and the redesign of the crank axle for fatigue prevention on the working replica of Robert Stephenson's 'Planet' locomotive at the Museum of Science and Industry in Manchester. 